\title{
27-Hydroxycholesterol Promotes Oligodendrocyte Maturation - Implications for Hypercholesterolemia Associated Brain White Matter Changes
}

\section{Vilma Alanko}

Karolinska Institutet

Tania Quintela-López

University of the Basque Country: Universidad del Pais Vasco

Adhara Gaminde-Blasco

University of the Basque Country: Universidad del Pais Vasco

Raúl Loera-Valencia

Karolinska Institutet

Alina Solomon

University of Eastern Finland - Kuopio Campus: Ita-Suomen yliopisto - Kuopion kampus

Ingemar Björkhem

Karolinska Institutet

Angel Cedazo-Minguez

Karolinska Institutet

Silvia Maioli

Karolinska Institutet

Graziella Tabacaru

Karolinska Institutet

María Latorre-Leal

Karolinska Institutet

\section{Carlos Matute}

University of the Basque Country: Universidad del Pais Vasco

Miia Kivipelto

Karolinska Institutet

Elena Alberdi

University of the Basque Country: Universidad del Pais Vasco

Anna Matton ( $\nabla$ anna.matton@ki.se )

Karolinska Institutet https://orcid.org/0000-0002-7819-0495

Research article 
Keywords: 27-hydroxycholesterol, oligodendrocyte, myelin, oligodendrocyte progenitor cell, white matter, neurodegeneration

Posted Date: May 5th, 2021

DOI: https://doi.org/10.21203/rs.3.rs-459275/v1

License: (1) This work is licensed under a Creative Commons Attribution 4.0 International License. Read Full License 


\section{Abstract}

Background: Midlife hypercholesterolemia is a risk factor for dementia, possibly via vascular-related pathways. Another proposed factor linking elevated systemic cholesterol levels and neurodegenerative diseases is the oxidized cholesterol metabolite 27 -hydroxycholesterol $(27-\mathrm{OH})$ that is able to pass the blood-brain barrier. High levels of 27-OH harm neuronal integrity and function, yet the effect of high 27$\mathrm{OH}$ levels on oligodendrocyte function remains unexplored. Since abnormal myelin structure results in the disconnection of neural networks that is an early phenomenon in neurodegenerative diseases, this study aimed to determine whether $27-\mathrm{OH}$ affects myelination in the brain.

Methods: Effects of 27-OH treatment were investigated both in isolated and co-cultured oligodendrocytes. Transgenic female mice with increased systemic 27-OH levels (Cyp27Tg) underwent behavioural testing and their brains were immunohistochemically stained and lysed for immunoblotting. CSF samples from a memory clinic cohort were analysed for associations between $27-0 \mathrm{H}$ and myelin proteins.

Results: Whereas human oligodendroglioma cells were resistant to high levels of $27-\mathrm{OH}(10 \mu \mathrm{M})$, cell death was induced in primary rat oligodendrocytes already at low concentrations $(0.5 \mu \mathrm{M})$. Long-term effects from treatment with $1 \mu \mathrm{M}$ 27-OH stimulated differentiation of oligodendrocytes in murine 3D cocultures. Female Cyp27Tg mice demonstrated learning deficits in the Morris Water Maze compared to non-transgenic littermates. Levels of myelin basic protein were increased in the corpus callosum of Cyp27Tg mice but adenomatous polyposis coli clone 1 (CC1) and platelet-derived growth factor receptor a (PDGFR1a) were unaltered, while levels of myelin oligodendrocyte glycoprotein were decreased in myelin enriched fractions. Levels of $27-\mathrm{OH}$ in the CSF of memory clinic patients were associated with increased levels of the oligodendrogenesis regulating enzyme 2',3'-Cyclic-nucleotide 3'-phosphodiesterase (CNPase; $\beta=0.38, p=0.022$ ).

Conclusions: The hypercholesterolemia associated $27-\mathrm{OH}$ alters the rate of differentiation from progenitor cells into mature oligodendrocytes and influences oligodendrocyte viability suggesting that 27$\mathrm{OH}$ reduces the oligodendrocytic ability for appropriate remodelling in the ageing brain by reducing the pool of progenitor cells.

\section{Background}

Factors related to lifestyle play a pivotal role in increasing the risk of developing neurodegenerative disorders (1). Midlife hypercholesterolemia has been linked to both late- and early-onset Alzheimer's disease (AD) $(2,3)$, and hypercholesterolemia is also one of the risk factors for vascular dementia (VaD) (4), but the mechanisms behind these links are not fully understood. The role of cholesterol metabolism in neurodegeneration is further corroborated by the association between familial hypercholesterolemia and cognitive deficits (5). Nonetheless, cholesterol is unable to penetrate the blood-brain barrier (BBB) and therefore the brain synthesises cholesterol de novo (6), suggesting that there are secondary factors that link high systemic cholesterol to neurodegeneration such as atherosclerosis and lesions of the white 
matter $(7,8)$. Oxysterols, which are metabolites of cholesterol, are emerging in research as biologically active compounds. Unlike cholesterol, oxysterols are able to traverse the BBB $(9,10)$.

The peripherally abundant 27-hydroxycholesterol $(27-\mathrm{OH})$ has been suggested to be the missing link between hypercholesterolemia and $A D(11,12)$. 27-OH is produced by the enzyme sterol 27-hydroxylase (CYP27A1) that is expressed throughout the body (9, Human Protein Atlas available from http://www.proteinatlas.org). The majority of $27-0 \mathrm{H}$ in the brain has its origin outside the central nervous system (CNS) (9). 27-OH fluxes into the brain in a concentration-dependent manner where it is unevenly distributed: the concentrations are higher in white than grey matter (9). 27-OH concentrations are relatively low overall, but both brain (14) and cerebrospinal fluid (CSF) $(15,16)$ levels are increased in neurodegenerative diseases compared to healthy controls. In elderly persons at risk of dementia in the multimodal intervention RCT FINGER, high 27-OH was associated with reduced memory and decreased hippocampal volume (17). The effects from excess brain levels of $27-\mathrm{OH}$ are diverse; impaired morphology of neurons and reduced dendritic spine density in the hippocampus (18), decreased glucose uptake of neurons (19), induced inflammatory responses (20), and cognitive decline in mice (19). Recently, oxysterols were even observed to activate astrocytes, which in turn similarly compromised neurons as when neurons are directly exposed to $27-\mathrm{OH}(21)$.

White matter changes are a key factor in lipid dyshomeostasis associated neurodegenerative diseases and dementia. Acknowledgement of this has emerged during the past couple of decades and is drawing increasing attention - not only in multiple sclerosis that represents the standard paradigm of demyelinating diseases $(22,23)$. White matter changes and notable demyelination have been associated with neurodegenerative diseases like AD, VaD, Parkinson's disease, Huntington's disease, and dementia with Lewy bodies (24-28). White matter hyperintensities $(\mathrm{WMH})$ seen in magnetic resonance imaging (MRI) or computed tomography (CT) scans are associated with cognitive impairment (29). WMHs indicate the existence of myelin lesions and they are traditionally considered to originate from vascular damages (29). This perception could be attributed at least to some extent to $27-0 \mathrm{H}$, as it plays a role in vascular pathologies such as atherosclerosis and the brain's renin-angiotensin system $(15,30)$. Nevertheless, it is unlikely that vascular pathologies solely underlie white matter changes. Changes in white matter integrity that have been detected in AD do not occur randomly; rather, the demyelination follows the inverse order of myelogenesis $(31,32)$, denoting a contradiction with the vascular aetiology.

Although the loss of myelin and reduced oligodendrocyte progenitor cell (OPC) proliferation are naturally occurring phenomena during ageing (33), the white matter changes are more substantial in neurodegenerative disorders. Moreover, changes in white matter integrity emerge in the early stages of neurodegeneration (34) which may provide a window of opportunity for new treatment strategies. For instance, in studies conducted on asymptomatic subjects with an increased risk of developing AD, a decline in white matter integrity has been associated with pathological AD biomarker levels (35). Despite these discovered associations, the role of myelin and oligodendrocytes in neurodegenerative progress remains relatively poorly studied. 
Maturation of OPCs is essential for restoring some lost functions caused by demyelination (36). OPCs are vulnerable to several factors, including oxidative stress, amyloid-beta (A $\beta)$, and age (37-39). Furthermore, along with ageing, properties and functionality of OPCs alternate both inter- and intraregionally in the brain resulting in a heterogeneous group of OPC subtypes (40), which subsequently may influence the remyelinating capacity of these cells. Regarding impacts of $A B$ on oligodendroglia, contradictory results exist; in several studies, $A \beta$ has been observed to induce proliferation and maturation of oligodendrocytes, and even remyelination of myelin lesions in cell and animal models $(41,42)$, while in others OPCs have been observed to lose their ability to proliferate in A $\beta$ plaque environment $(43,44)$. Exogenous agents may also affect OPCs. Statins induce the maturation of OPCs thus depleting the pool of progenitors (45). Hence, if OPCs go into senescence or initiate needless maturation processes, their capacity to remyelinate at later occasions would be insufficient.

$27-\mathrm{OH}$ reduces cholesterol synthesis in vitro and in vivo $(46,47)$, which raises concerns regarding proper myelin assembly and maintenance for which adequate cholesterol levels are essential. Still, to our knowledge, how 27-OH affects oligodendrocytes and myelination-related processes remain unknown. Here, we investigated whether $27-\mathrm{OH}$ influences oligodendrocyte maturation profile and myelin integrity. First, the impacts of $27-\mathrm{OH}$ treatment on cell viability in cultured oligodendrocytes were studied, whereafter maturation was assessed. Myelin RNA and protein levels were measured in primary 3D cocultures from mice. Learning and memory of female mice overexpressing sterol 27-hydroxylase (Cyp27Tg) and age-matched non-transgenic littermates ( $\mathrm{Tg}^{-}$) were assessed with a battery of cognitive tests, and brain sections stained for markers of immature and mature oligodendrocytes, and myelin content. Lastly, associations between $27-\mathrm{OH}$ and myelination proteins in CSF samples from memory clinic patients were analysed.

\section{Methods}

\section{Cell viability assay}

The Human Oligodendroglioma (HOG) cell line (Millipore, Burlington, MA, USA) is a clonal cancer cell line and originates from a surgically removed oligodendroglioma from a human patient. The cell line is described in more detail by Post and Dawson, and Buntinx et al. $(48,49)$. The cells were cultured in DMEM media (Gibco, Thermo Fisher Scientific, Waltham, MA, USA) with 10\% heat-inactivated FBS (Gibco) and maintained at $37^{\circ} \mathrm{C} 5 \% \mathrm{CO}_{2}$.

Cell viability assays for HOG cells and primary oligodendrocytes were performed with Calcein AM Cell Viability Assay (R\&D Systems, Minneapolis, Minnesota, USA). HOG cells were seeded into 96-well plates at a density of 8000 cells per well. After 1 day in vitro, cells were incubated for $24 \mathrm{~h}$ with either $56.4 \mathrm{mM}$ DMSO (Sigma-Aldrich, Saint Louis, Missouri, USA) (volume corresponding to that of $10 \mu \mathrm{M} 27-\mathrm{OH}$ treatment), $282 \mathrm{mM}$ DMSO (volume corresponding to that of $50 \mu \mathrm{M} 27-\mathrm{OH}$ treatment), $1 \mu \mathrm{M}, 10 \mu \mathrm{M}$, or 50 $\mu \mathrm{M}$ 27-OH (Avanti Polar Lipids, Alabaster, AL, USA). 27-OH was diluted in DMSO. Non-treated (data not shown) and $0.1 \mathrm{mM} \mathrm{H}_{2} \mathrm{O}_{2}$ treated cells were included as negative and positive controls, respectively. The 
assay was performed according to the manufacturer's instructions using a $2 \mu \mathrm{M}$ Calcein AM Working Solution. The fluorescence of the plates was read with BMG Fluostar Galaxy (BMG Labtechnologies, Offenburg, Germany) with an excitation filter of $492 \mathrm{~nm}$ and an emission filter of $520 \mathrm{~nm}$, and results were processed with its software (version 4.31-0).

For cell viability assay in 2D primary oligodendrocytes, tissue was obtained from optic nerves of 12-daysold Sprague Dawley rats, as described previously (50). Cells were seeded into $24-w e l l$ plates bearing $12-$ mm-diameter coverslips coated with poly-D-lysine $(10 \mathrm{mg} / \mathrm{ml})$ at a density of $1 \times 10^{4}$ cells per well. Cells were maintained at $37^{\circ} \mathrm{C}$ and $5 \% \mathrm{CO}_{2}$ in a chemically defined medium (50). After 1 day in vitro, cultured oligodendrocytes were treated with increasing concentrations of DMSO or 27-OH $(0.1-10 \mu \mathrm{M})$ for $24 \mathrm{~h}$, as is indicated above. Cultured oligodendrocytes were incubated with Calcein-AM (Life Technologies, Carlsbad, CA, USA) at $1 \mu \mathrm{M}$ and $37^{\circ} \mathrm{C}$ for $30 \mathrm{~min}$ in fresh culture medium and thereafter washed in prewarmed 0.1 M PBS three times. Emitted fluorescence was measured by a Synergy HT (Biotek, Winooski, Vermont, USA) spectrophotometer using excitation wavelength at $485 \mathrm{~nm}$ and emission at $528 \mathrm{~nm}$.

\section{Primary 3D co-cultures}

For 3D cell culturing C57/BLJ6 mice were used. Female mice were let to breed with males overnight to ensure accurate embryonic day (E) of the embryos used for primary cell cultures. At E16 - E17, the embryos were sacrificed by decapitation, heads of the embryos were collected and, kept in Hibernate ${ }^{\mathrm{TM}}-\mathrm{E}$ Medium (Gibco) until dissection of brains. Dissection was performed in EBSS solution (Life Technologies) and only dissected hippocampus and cortex were used for the co-culture set-up.

To extract the cells from the tissue, tissues were first incubated at $37^{\circ} \mathrm{C}$ in a $1: 1$ mix of solution $\mathrm{A}$ ( $0.0625 \%$ trypsinization solution [Life Technologies] in EBSS) and solution B $(0.08 \mathrm{mg} / \mathrm{ml}$ DNAse I solution [Roche, Basel, Schweiz] in EBSS) for approximately 15 min gently moving. Trypsinization was stopped with $10 \%$ heat-inactivated FBS or culture media \#1 containing 2\% B27 supplement (Gibco), $1 \%$ N2 supplement (Gibco), 100 units/ml penicillin and $100 \mu \mathrm{g} / \mathrm{ml}$ streptomycin (Thermo Fisher Scientific), in DMEM/F-12 + GlutaMAX (Gibco). After supernatant removal, the tissue was mechanically disintegrated by pipetting up and down in culture media. The supernatant containing the cells was collected and centrifuged at $500 \mathrm{xg}$ for $5 \mathrm{~min}$.

For immunocytochemistry, pellet was thereafter resuspended in a new culture media \#2 containing a 1:1 mix of Neurobasal media and DMEM/F12 + GlutaMAX, 0.5\% GlutaMAX supplement (Gibco), 2\% B27, 1\% $\mathrm{N} 2$, and $50 \mathrm{ng} / \mathrm{ml} \mathrm{NGF}$ (Gibco). For 3D culture droplets, diluted cell suspension and Matrigel (Corning Life Science, Corning, NY, USA) were mixed 1:1 to reach droplet sizes of $50 \mu$ l. Droplets were cultured in individual dishes precoated with poly-D-lysine (MatTek, Ashland, MA, USA). Approximately 15,000 cells were seeded in each droplet. Droplets were let to settle for $1 \mathrm{~h}$ before adding $2 \mathrm{ml}$ of the culture media \#2. Cultures were treated at DIV1 with $1 \mu \mathrm{M} 27-\mathrm{OH}$ or $5.6 \mathrm{mM}$ DMSO. Non-treated cultures were included as negative controls (data not shown). Two-thirds of media were replaced every four days until fixation and immunofluorescence (IF) analysis. Cultures were maintained at $37^{\circ} \mathrm{C} 5 \% \mathrm{CO}_{2}$ and fixed at DIV20. 
For the time-course study, the pellet was resuspended in culture media $\# 1.110,000-125,000$ cells were seeded per $75 \mu \mathrm{l}$ droplet with Matrigel in a ratio of 1:1. Droplets were let to settle for $1 \mathrm{~h}$ before adding 1 $\mathrm{ml}$ of the culture media \#1. Cultures were treated at DIV1 with $1 \mu \mathrm{M} 27-\mathrm{OH}$ or $5.6 \mathrm{mM}$ DMSO. Cultures were maintained at $37^{\circ} \mathrm{C} 5 \% \mathrm{CO}_{2}$ until harvesting at DIV3, 5 or 10 , by removing media, washing with PBS, and lysing with 300-350 $\mu$ RLT buffer (Qiagen, Hilden, Germany).

\section{Immunofluorescence staining in 3D cultures}

3D cell cultures were fixed with $2 \%$ methanol-free formaldehyde (Thermo Fisher Scientific) for 5 min at RT. Cultures were blocked and permeabilised with 0.3\% Triton X-100 (Sigma-Aldrich), 5\% BSA in PBS for 1 $h$ at RT. Primary antibodies were diluted in the blocking/permeabilization buffer and incubated overnight at RT. Secondary antibodies were diluted in the same buffer and were incubated for $2 \mathrm{~h}$ at RT in dark. To observe mature oligodendrocytes and oligodendrocyte linage cells following primary antibodies were used: oligodendrocyte marker mouse anti-MBP 1:500 (ab62631, Abcam, Cambridge, UK), and oligodendrocyte linage marker goat anti-Olig2 1:20 (AF2418, R\&D Systems). Secondary antibodies used were Alexa Fluor 633-conjugated goat anti-mouse 1:500 (A21052, Invitrogen, Thermo Fisher Scientific), Alexa Fluor 488-conjugated donkey anti-goat 1:1000 (A11055, Invitrogen), and DAPI 405nm 1:1000. After antibody incubations, coverslips were mounted on the cultures with $90 \%$ glycerol.

A Nikon Eclipse Ti spinning disk confocal microscope using 20X objective coupled to a camera with a pixel size of $6.45 \mu \mathrm{m}$ was used to image the cultures, and images were processed with NIS-Element software (version 5.11.02, Nikon, Tokyo, Japan). The images were further analysed using Imaris x64 software (version 5.9.0, Oxford Instruments, Zurich, Switzerland) by creating surfaces of desired channels: DAPI alone represented the total number of cells, Olig2 ${ }^{+}$DAPI colocalization the cells that are of oligodendrocyte lineage, $\mathrm{MBP}^{-}$Olig2 ${ }^{+} \mathrm{DAPI}$ colocalization immature oligodendrocytes, and $\mathrm{MBP}^{+}$ Olig2+ DAPI colocalization represented the mature oligodendrocytes.

\section{Quantitative PCR (qPCR)}

RNA was isolated from 3D cultures using the RNeasy ${ }^{\circledR}$ Mini Kit (Qiagen), following the manufacturer's protocol. The concentration and quality of the RNA were measured with a nanodrop spectrophotometer (NanoDrop 1000, Thermo Fisher Scientific). Reverse transcription was performed in the S1000 Thermal cycler (Applied Biosystems, Thermo Fisher Scientific) to yield cDNA using a standardised protocol for high-capacity cDNA reverse transcription (Thermo Fisher Scientific).

Gene expression of Pdgfra (Mm00440701_m1, Life Technologies), Cc1 (Mm00545872_m1, Life Technologies), Olig2 (Mm01210556_m1, Life Technologies), and Gapdh (4352339E, Life Technologies) in primary cells from the time-course experiment was analysed by qPCR according to a standardised protocol for TaqMan ${ }^{\text {TM }}$ gene expression assay (Thermo Fisher Scientific), using the 7500 Fast Real-Time PCR System (Applied Biosystems). Copy numbers of Pdgfra (platelet-derived growth factor receptor a) and Cc1 (adenomatous polyposis coli clone 1) mRNAs were adjusted by mRNA copy numbers of Olig2. 
As an internal control, mRNA copy numbers of Olig2 were adjusted by copy numbers of Gapdh. The relative values of mRNA copy numbers were compared to the numbers in DMSO-treated DIV3 cultures.

\section{CYP27 transgenic mice}

8-month-old female, human sterol 27-hydroxylase overexpressing, transgenic mice (Cyp27Tg) and their age-matched non-transgenic littermates ( $\left.\mathrm{Tg}^{-}\right)$underwent behavioural studies. We studied two separate cohorts: For Morris Water Maze we tested 10 transgenic and 10 non-transgenic mice and for Y-maze and Fear Conditioning 9 transgenic and 5 non-transgenic mice. Cyp27Tg mice overexpress human CYP27A1 and have higher amounts of 27-OH when compared to WT mice, described in more detail by Meir et al. and Ali et al. $(46,47) .4 \mathrm{Tg}$ - and 4 Cyp27Tg mouse brain samples were used for Western blotting of total brain homogenates. Myelin enriched fractions were retrieved from $4 \mathrm{Tg}$ - and 7 Cyp27Tg mouse brains.

\section{Behavioural tests}

Morris Water Maze was performed as described by Maioli et al. (51). Each mouse was tested for four trials per day, for five consecutive days. Reference memory was evaluated on the sixth day (probe test).

Y-maze was performed as described by Eroli et al. (52). The fear conditioning test was performed as described by Eroli et al. (52), with the supplementation of the conditional stimulus of sound on day one. Mice were exposed to a $55 \mathrm{~dB}$ sound at $5000 \mathrm{~Hz}$ that lasted for 30 seconds and was followed by a mild foot shock ( $0.3 \mathrm{~mA}$ for $2 \mathrm{sec}$ ). The sound-shock pairing was repeated three times in total with a 50 -sec interval between each one. Cue fear conditioning was performed on day three, where mice were let to explore the new surrounding for 2 min, whereafter the sound ( $55 \mathrm{~dB}$ at $5000 \mathrm{~Hz}$ ) lasted for 2 minutes continuously. The rectangular-shaped chamber was replaced for a round-shaped chamber $(20 \mathrm{~cm}$ diameter x $35 \mathrm{~cm}$ high), and the stainless-steel grid floor was replaced for a black flat surface. Instead of wiping the chamber with ethanol, the chambers were cleaned between each mouse with hypochlorous water (50\% dil). Freezing behaviour was defined as the complete absence of mobility within the same area for 2 seconds or longer and was measured through TSE Multi Conditioning software. The freezing \% recorded during the habituation phase of day 1 (as a measure of baseline freezing) was compared to freezing \% of day 2 to evaluate the context memory. To assess the cue memory, we measured the freezing \% on day 3 before and during the sound stimulus.

\section{Deparaffinisation of mouse brain sections}

Paraffin-embedded mouse coronal brain sections of adult Cyp27Tg mice and Tg - mice were used for Luxol fast blue (LFB) staining of myelin and IF staining of PDGFRa and CC1. For both IF and LFB, two sections from three different mice and genotype were deparaffinised by serial incubations in xylene or Histolab-Clear (HistoLab, Gothenburg, Sweden) and ethanol (EtOH) of decreasing concentrations (xylene or Histolab-Clear: 2x 10 min, 99.5\% EtOH: 2x 5-10 min, 95\% EtOH: 1x 3-5 min, 70\% EtOH: 1x 3-5 min), after which they were washed in deionised water.

\section{Luxol blue staining of mouse brain sections}


For myelin staining, the Luxol Fast Blue Stain Kit (Abcam) was used. Brain sections were incubated in LFB for $2 \mathrm{~h}$ at $60^{\circ} \mathrm{C}$. After incubation, slides were rinsed thoroughly with distilled $\mathrm{H}_{2} \mathrm{O}$ and thereafter dipped in lithium carbonate for differentiation. Differentiation was continued by dipping the slides into $70 \%$ alcohol reagent until the grey matter was colourless. Additional sections were incubated with cresyl echt violet for $1 \mathrm{~min}$ at RT to confirm that tissue morphology is maintained during LFB staining (images not shown). After incubation, slides were quickly rinsed with distilled $\mathrm{H}_{2} \mathrm{O}$, and sections were dehydrated with three changes in $99.5 \%$ ethanol. Sections were mounted on coverslips with Vecta Mount mounting media. Images were acquired with Nikon Eclipse E800 light microscope, using a 10X objective, coupled to a Nikon DS-Ri2 camera and processed with NIS-Elements imaging software (version 4.30.00). Blinded analysis of LFB stained sections was performed using ImageJ 1.52p (53) as described previously by Underhill et al. 2011 and Khodanovich et al. 2017 (54,55). The mean intensity of each brain section was measured from corpus callosum and fimbria. Mean intensities of the red channel ( $\left.I_{R}\right)$ in ROls (Fig. 4A) were measured from RGB images of LFB stained sections without cresyl echt violet stain. Similarly, the mean intensity of the background $\left(\mathrm{I}_{\mathrm{B}}\right)$ was measured in each image. Optical densities (\%) of each region were calculated as $100 \times(1-[\mathrm{IR} / \mathrm{IB}])$, resulting in higher myelin content with increasing value.

\section{Immunofluorescence staining of mouse brain sections}

Immunofluorescence (IF) for MBP was performed on free-floating sections. Slices were permeabilized and blocked in $4 \%$ normal goat serum (NGS), $0.1 \%$ Triton X-100 in PBS (blocking buffer) for $1 \mathrm{~h}$ and incubated overnight at $4^{\circ} \mathrm{C}$ with primary antibody against MBP (SMI 99, 1:1000; Biolegend, San Diego, CA, USA). Slices were washed in PBS and incubated with fluorophore-conjugated Alexa secondary antibody (1:500) in blocking buffer for $1 \mathrm{~h}$ at RT. Samples were mounted with Fluoromount-G. Images were acquired with Zeiss AxioVision microscope using a 10X objective and analysis was carried out in 2-3 sections per subject. Images were taken with the same setting for all experiments and mean intensity values were quantified from corpus callosum and cortex with Image $\mathrm{J}$ software.

For IF of $\mathrm{CC} 1$ and PDGFRa in deparaffinised tissue, a heat-induced treatment $\left(95^{\circ} \mathrm{C}\right.$ for $\left.5 \mathrm{~min}\right)$ in RUniversal buffer (Aptum, Southampton, UK) was performed on all sections for epitope recovery. The sections used for $\mathrm{CC} 1$ staining were washed with cold PBS and treated with ice-cold $100 \%$ EtOH for 10 min at $-20^{\circ} \mathrm{C}$. This step was not performed on the sections used for PDGFRa staining. The sections were blocked for $1 \mathrm{~h}$ at RT in blocking buffer with $0.3 \%$ Triton X-100, 10\% NGS (Vector Laboratories, Burlingame, CA, USA) in PBS. The sections were then incubated with mixtures of primary antibodies rat anti-PDGFRa 1:100 (562777, BD Biosciences, San Jose, CA, USA) or mouse anti-CC1 1:200 (OP80, Millipore) together with anti-NeuN (ABN78, Sigma-Aldrich) in incubation buffer (0.3\% Triton X-100, 10\% NGS, $1 \%$ BSA) overnight at $4^{\circ} \mathrm{C}$. Sections were incubated with goat anti-rat Alexa Fluor 488 1:300 (A11006, Invitrogen) or Goat anti-mouse Alexa Fluor 488 1:300 (A28175, Invitrogen) and anti-NeuN and DAPI 1:1000 secondary antibodies for $2 \mathrm{~h}$ at RT and protected from light. Finally, the sections were treated with an autofluorescence eliminator reagent (Millipore) for 5 minutes to reduce autofluorescence and mounted with SlowFade ${ }^{\text {TM }}$ Gold Antifade (Thermo Fisher Scientific). The stained tissue was analysed 
using a confocal microscope (Zeiss LSM-800 Airy system) with a 20X objective. Three pictures from each region, corpus callosum, cortex, and hippocampus, were captured from one section of each mouse using the Zen software (ZEISS Microscopy, Jena, Germany). Imaging settings were kept constant for each staining type. In a blinded experiment, the number of PDGFRa and CC1 positive cells were quantified for each region (total area of approximately $918 \mathrm{~mm}^{2} /$ region) by one rater.

\section{Preparation of myelin enriched fractions}

Dissected brains were removed from meninges, choroid plexus, cerebellum, and the brainstem. Brains were minced in DMEM. Total brain homogenates were incubated with $2.5 \mathrm{mg} / \mathrm{ml}$ DNAse I and $2.5 \mathrm{mg} / \mathrm{ml}$ Trypsine/EDTA for $30 \mathrm{~min}-1 \mathrm{~h}$ at $37^{\circ} \mathrm{C}$ on an orbital shaker at $180 \mathrm{rpm}$ for tissue digestion. Thereafter, tissue suspension was mixed with DMEM and centrifuged at $1000 \mathrm{xg}$ for $10 \mathrm{~min}$ at $4^{\circ} \mathrm{C}$. Pellet was then resuspended in $20 \% \mathrm{w} / \mathrm{v}$ BSA-DMEM and centrifuged $1000 \mathrm{xg}$ for $20 \mathrm{~min}$ at $4^{\circ} \mathrm{C}$. The upper layer (myelin) was collected using a pasteur pipette.

\section{Immunoblotting of brain and cerebrospinal fluid}

Brains were homogenated with a douncer in RIPA buffer ( $50 \mathrm{nM}$ Tris pH 7.5, $150 \mathrm{mM} \mathrm{NaCl}, 0.5 \%$ sodium deoxycholate, $0.1 \%$ SDS, $1 \%$ NPO-40 in 0.1 M PBS) supplemented with protease inhibitor cocktails (Roche). Afterwards, they were sonicated for 25 cycles at 80\% amplitude (Labsonic M, Sartorius, Göttingen, Germany), centrifuged for 10 minutes at $1,200 \mathrm{rpm} 4^{\circ} \mathrm{C}$, and the supernatants were collected. Total protein content was quantified through Bradford assay (Bio-Rad, Hercules, CA, USA) and all the samples were brought to the same concentration. Samples were mixed with $1 \mathrm{X}$ sample buffer $(62.5 \mathrm{mM}$ Tris ph $6.8,10 \%$ glycerol, $2 \%$ SDS, $0.002 \%$ bromophenol blue, and $5.7 \% \beta$-mercaptoethanol in $\mathrm{dH}_{2} 0$ ) and boiled at $95^{\circ} \mathrm{C}$ for $8 \mathrm{~min}$.

For myelin enriched fractions, $25 \mu \mathrm{l}$ of each sample was mixed with $25 \mu \mathrm{l}$ of $2 \mathrm{X}$ sample buffer. This process was performed on ice to enhance the lysis process and avoid protein degradation. Samples were boiled at $95^{\circ} \mathrm{C}$ for $8 \mathrm{~min}$. Consequently, they were centrifuged for 1 minute at $14,000 \mathrm{xg}$ and the supernatants were collected. Then, total protein content was quantified through RC DC Protein Assay (Bio-Rad) and all the samples were brought to the same concentration. Finally, they were boiled again at $95^{\circ} \mathrm{C}$ for 8 minutes.

Brain homogenates ( $10 \mu \mathrm{g}$ per sample), myelin enriched fractions ( $20 \mu \mathrm{g}$ per sample) and CSF (11.25 $\mu$ l) were size-separated by sodium dodecyl sulfate-polyacrylamide gel electrophoresis (SDS-PAGE) in 4-20\% Criterion TGX Precast gels and transferred to nitrocellulose membranes using a Trans-Blot Turbo Transfer System (Bio-Rad). Membranes were blocked in 5\% BSA in Tris-buffered saline/0.05\% Tween-20 (TBS-T) and proteins detected by specific primary antibodies against MBP (SMI 99, 1:1000; Biolegend), PLP (MAB388, 1:1000, Millipore), MOG (MAB5680, 1:1000, Millipore), CNPase (C5922, Sigma-Aldrich), and $\beta$ actin (A20066, 1:5000; Sigma-Aldrich).

\section{CSF sampling and clinical biomarkers}


CSF samples were collected by standard lumbar puncture between the L3/L4 or L4/L5 intervertebral space using a 25-gauge needle. CSF was aliquoted in polypropylene tubes and stored at $-80^{\circ} \mathrm{C}$ until further analysis. CSF A $\beta_{42}$, t-Tau, and p-Tau concentrations were measured on fresh samples with commercially available sandwich enzyme-linked immunosorbent assays (Innogenetics, Ghent, Belgium) according to standardized protocols in the clinic. $27-\mathrm{OH}$ levels were quantified in cerebrospinal fluid using isotope dilution mass spectrometry as described previously (56).

\section{Statistical analysis}

Analyses were carried out using Prism (version 8.2.1, GraphPad, San Diego, CA, USA), except for CSF data which were analysed using Stata software (version IC 16.1, StataCorp LLC, College Station, Texas, USA). Results are expressed as mean values and standard deviations. Data obtained from cell and animal studies were analysed with a two-tailed t-test, Mann-Whitney two-tailed U-test, one-way ANOVA, or repeated-measures ANOVA when appropriate. In the case of ANOVA, adjusted $p$-values are reported. Normality of data was assessed with the Shapiro-Wilk test, and for CSF data with skewness and kurtosis tests for normality. Zero-skewness log transformation was applied to skewed variables. For analysis of associations of CSF data, four linear regression models were applied. In Model 1 adjustment was made for age and sex. In Model 2 adjustment was made for age, sex, and $A \beta_{42}$. In Model 3 adjustment was made for age, sex, and t-Tau. In Model 4 adjustment was made for age, sex, and p-Tau. In all models, myelin proteins were considered dependent variables and $27-\mathrm{OH}$ an independent variable. In all analyses, a $p$-value of $<0.05$ was considered significant.

\section{Results}

\section{7-OH treatment exhibits toxicity in cultured oligodendrocytes}

First the impact of 27-OH on oligodendrocyte viability was investigated in primary oligodendrocytes derived from rat optic nerves and human oligodendroglioma (HOG) cells. In primary oligodendrocytes, cell viability decreased with increasing concentrations of $27-\mathrm{OH}$, with a significant decline at $0.5 \mu \mathrm{M}(9.3 \%$ [3.5] of control, $p=0.020$, Fig. $1 \mathrm{~A}$ ). However, the reduction in cell viability showed a trend already at 0.1 $\mu \mathrm{M}(5.6 \%$ [3.2] $p=0.070)$. The difference in $1 \mu \mathrm{M}$ treated cells was $13.4 \%(2.6, p=0.002)$, in $5 \mu \mathrm{M}$ treated $19.8 \%(5.9, p=0.009)$, and in $10 \mu \mathrm{M}$ treated $20.3 \%(4.2, p=0.003)$. Cell death was not observed in HOG cells at the same concentrations (Fig. 1B). Rather, cell death in HOG cells was not evident until $50 \mu \mathrm{M}$ concentration (57.9\% [16.3], $p=0.002) .0 .1 \mathrm{mM} \mathrm{H}_{2} \mathrm{O}_{2}$ was used as positive control for the experiment $(97.9 \%[4.4]$ decrease, $p<0.0001)$.

\section{7-OH promotes maturation of oligodendrocytes in 3D co- cultures}


Next, long-term effects from 27-OH treatment $(1 \mu \mathrm{M}, 20$ days-in-vitro (DIV)) on oligodendrocyte number and maturation were studied in primary 3D co-cultures. After 20 DIV, the ratio of oligodendroglial cells (Olig2 ${ }^{+}$; oligodendrocyte transcription factor 2 ) to the total cell number remained similar in both control and 27-OH treated cultures ( $p=0.144$, Fig. 2A \& B) indicating low long-term toxicity. The proportion of immature oligodendrocytes ( $\mathrm{MBP}^{-} \mathrm{Olig} 2^{+}$; myelin basic protein) significantly decreased in $27-\mathrm{OH}$ treated cultures (0.8-fold [0.1], $p=0.004$, Fig. $2 \mathrm{C})$, while the relative level of mature cells $\left(\mathrm{MBP}^{+} \mathrm{Olig} 2^{+}\right)$showed a non-significant increment (0.6-fold [0.2], $p=0.068$, Fig. 2D).

Since the 3D co-cultures were treated at DIV1 and we know that 27-OH is rapidly metabolised (57), we next sought to determine early and mid-term effects from $27-\mathrm{OH}$ treatment by measuring RNA levels of oligodendrocyte maturation markers at different time-points. The expression of the oligodendrocyte marker Olig2 in 27-OH treated cultures was decreased on DIV3 and 5 but not at DIV10 compared to control (0.7-fold [SE 0.2] $p=0.053,1.2$-fold [0.2] $p=0.001$, and 0.1-fold [0.2] $p=0.999$, respectively). respectively, Fig. 2E), indicating a transient reduction in the oligodendrocyte population in relation to other cell types. In DMSO treated cultures, Olig2 expression was stable from DIV3 to DIV5, but on DIV10 there was a significant reduction in expression when compared to DIV5 (0.7-fold [0.2], $p=0.037$ ). Compared to control cells, there was a reduction in the OPC marker Pdgfra expression by $27-\mathrm{OH}$ treatment evident at all time points (Fig. 2F), yet the differences did not reach significance. At the first time point, the magnitude of reduction was on average 0.8 -fold $(0.3, p=0.068)$. On DIV 5 the reduction attenuated slightly to 0.6 -fold $(0.2, p=0.105)$. The difference between treatments remained at a similar level at DIV10 as on the earlier time points ( 0.7 -fold [0.2] reduction, $p=0.061$ ). Overall, the expression of $P d g f r a$ did not vary within DMSO nor the $27-\mathrm{OH}$ treated cultures between time points. An opposing expression pattern of the marker of myelinating oligodendrocyte $C c 1$ was observed in the same cultures (Fig. 2G). CC1 expression exhibited a $5.0-$ fold $(0.8)$ increase in $27-0 \mathrm{H}$ treated cultures on DIV3 $(p<0.0001)$. The difference remained significant at DIV5, yet the magnitude of difference had decreased to 3.0 -fold $(0.7, p=0.006)$. However, by DIV10 the levels had attenuated to the levels of the control treatment $(p=0.287)$. Expression of $C c 1$ was stable in DMSO cultures throughout timepoints, but in $27-\mathrm{OH}$ treated cultures there was a reduction in expression from DIV3 to DIV5 (2.4-fold [0.8], $p=0.049$ ), and further from DIV5 to DIV10 (2.9-fold [0.7], $p=$ 0.008).

\section{Elevated levels of 27-OH result in impairment of spatial learning in female Cyp27 transgenic mice}

After assessing the exposure of $27-0 \mathrm{H}$ in cultured oligodendrocytes we next aimed to investigate the chronic effects of $27-\mathrm{OH}$ on the brain and myelin specifically. As a first step, we applied a battery of memory tests on female 8-month-old Cyp27Tg mice and their age-matched non-transgenic littermates $(\mathrm{Tg}-)$ to test spatial and fear-associated contextual learning and memory. In the Morris Water Maze (MWM), the latency to finding the platform significantly decreased in control mice from day one and two, up to day five (mean [SE] $31.0 \mathrm{~s}$ [7.5] $p=0.027$ and 22.7 $\mathrm{s}$ [5.9] $p=0.040$, respectively; Fig. 3A), indicating that the control group was able to learn the task. However, such learning was not evident in Cyp27Tg mice, where there were no statistically significant differences observed in escape latency between training 
days. When comparing the groups during the learning phase, control mice were $23.4 \mathrm{~s}(8.0)$ faster to find the platform than Cyp27Tg mice $(p=0.054$, Fig. 3A) on the last training day. The speed $(\mathrm{cm} / \mathrm{s})$ did not differ between strains (Cyp27Tg $18.1 \mathrm{~cm} / \mathrm{s}$ [3.0], control $19.9 \mathrm{~cm} / \mathrm{s}$ [1.7] $p=0.143$, Fig. 3B) excluding the possibility of differences observed in learning to be a result of lack in motivation or differences in motor function. On the 6th day (probe test) when the platform was removed, mice from both strains spent a similar amount of time in the target zone (Cyp27Tg $12.6 \mathrm{~s}$ [8.0], $\mathrm{Tg}-15.6 \mathrm{~s}$ [6.4], $p=0.356$, Fig. 3C).

In Y-maze, there was no significant difference between the percentage in alteration between arms (Cyp27Tg 58.5\% [13.4], $\mathrm{Tg}-62.5 \%$ [14.6], $p=0.613$, Fig. 3D). However, the number of entries into the different arms showed a trend towards significance between strains (Cyp27Tg 20.1 [4.8], Tg - 14.2 [5.8], $p$ $=0.063$, Fig. 3E). On the first day of Fear Conditioning (FC) mice were exposed to a high-frequency sound and an electric shock after the sound. On the second day, the floor was kept as in day 1 (context), but mice were not exposed to sound nor electrical shock. In both strains the time freezing increased significantly for second day (Cyp27Tg 29.9\% [4.5], Tg $-41.9 \%$ [6.0], for both $p<0.0001$, Fig. 3F). However, the amount of freezing during the second day was less for Cyp27Tg than for $\mathrm{Tg}$ - mice, yet the difference demonstrates a trend towards significance $(p=0.072)$. On the third day, mice were exposed to the same sound (cue) as on the first day on a new floor (change of context). Both strains increased their freezing time significantly during the sound compared to the time before sound (Cyp27Tg 47.2\% [6.1] $p<0.0001$, $\mathrm{Tg}-37.3 \%$ [8.2] $p=0.001$, Fig. 3G). There was no significant difference between strains in freezing time before sound $(p=0.100)$ nor during sound $(p=0.629)$.

\section{Chronic exposure to $27-0 \mathrm{H}$ in vivo does not alter myelin overall structure but increases MBP levels}

To assess overall myelin structure and level in the $\mathrm{Tg}$ - and Cyp27Tg mice, brain sections were stained with Luxol fast blue (LFB). Myelination of the corpus callosum at the age of 8 months did not differ between strains ( $p=0.427$, Fig. $4 C$ ). Neither was there a difference in LFB staining of fimbria between strains $(9.7 \%, p=0.108$, Fig. 4D). In order to investigate if oligodendrocyte maturation is enhanced and if there is a decrease in OPCs in Cyp27Tg brains, brain sections were stained for MBP, PDGFRa, and CC1. MBP expression was significantly increased in corpus callosum of Cyp27Tg brains (mean [SEM] difference 16.1 [5.7] $p=0.022$, Fig. 4), but not in cortex (7.3 [4.3], $p=0.129$, Fig. 5A-C).

Nevertheless, chronic exposure to 27-OH does not appear to have an impact on CC1 nor the PDGFRa at the age of 8 months since the number of positive cells were similar between transgenic and nontransgenic mice in all the analysed areas: cortex ( $p=0.106$ and $p=0.482$, respectively), corpus callosum ( $p=0.102$ and $p=0.926$, respectively), and hippocampus ( $p=0.552$ and $p=0.421$, respectively, Fig. 5DG). MBP levels of whole-brain homogenates did not differ between strains ( $p=0.940$, Fig. 6B), nor in myelin enriched fractions of brain homogenates $(p=0.503$, Fig. 6D). Levels of proteolipid protein (PLP) showed non-significant reduction ( $p=0.076$, Fig. $6 \mathrm{E})$ and myelin oligodendrocyte glycoprotein (MOG) a significant decreased in myelin enriched fractions of Cyp27Tg brains ( $p=0.024$, Fig. 6F). 


\section{7-OH levels in CSF associate with CNPase levels in memory clinic patients}

To study the associations between $27-\mathrm{OH}$ levels and proteins reflecting myelin integrity we further studied CSF samples from GEDOC memory clinic patients. Sociodemographic and clinical characteristics of the cohort are presented in Table 1. The results from the linear regression analyses are presented in Table 2. We did not observe any statistically significant associations between MBP and 27-OH in any of the models. Nonetheless, CNPase associated significantly with 27-OH in Model 1 ( $\beta=0.38, p=0.022$ ), and the significance remained even after further adjustment for AD-related pathologies, which are common in memory clinic patients: $A \beta_{42}, t-T a u$, and $p$-Tau levels. The results did not change even if models were further adjusted for cognition (data not shown). As expected, the CSF levels of myelin proteins MBP and CNPase were associated with each other (Model 1: $\beta=0.70, p<0.0001$ ). The myelin protein levels did not associate with the levels of AD biomarkers (data not shown), except for MBP which was associated with $A \beta_{42}(\beta=0.32, p=0.034)$. Neither did the myelin proteins associate with cognition as measured by RAVLT or MMSE when adjusted for age, sex, and education (data not shown). 
Table 1

Baseline characteristics of the memory clinic cohort

\begin{tabular}{|lll|}
\hline Demographic characteristics & $\mathbf{n}$ & Mean (SD) \\
\hline Sex, \% male/female & $33 / 57$ & $36.7 / 63.3$ \\
\hline Age, years & 90 & $67.7(10.1)$ \\
\hline Education, years & 90 & $12.1(3.5)$ \\
\hline Diagnosis, \% & & \\
\hline SCl & 30 & 33.3 \\
\hline MCl & 30 & 33.3 \\
\hline AD & 30 & 33.3 \\
\hline CSF measurements & & \\
\hline A ${ }_{42}$ (ng/l) & 90 & $838.6(323.7)$ \\
\hline t-Tau (ng/l) & 90 & $349.8(212.7)$ \\
\hline p-Tau (ng/l) & 90 & $61.6(28.7)$ \\
\hline 27-OH (ng/ml) & 86 & $1.10(0.35)$ \\
\hline 24-OH (ng/ml) & 86 & $2.05(0.67)$ \\
\hline MBP (a.u.) & 48 & $1.70(1.46)$ \\
\hline CNPase (a.u.) & 54 & $2.38(1.20)$ \\
\hline Cognition & & \\
\hline MMSE & 89 & $27.3(2.9)$ \\
\hline RAVLT & & \\
\hline
\end{tabular}

Table 2

Association between myelin proteins and $27-\mathrm{OH}$ in CSF

\begin{tabular}{|llllllllll|}
\hline & \multicolumn{3}{c}{ Model 1 } & \multicolumn{2}{c}{ Model 2 } & Model 3 & \multicolumn{2}{c|}{ Model 4 } \\
\hline Dependent variable & $\mathrm{n}$ & $\beta$ & $p$ & $\beta$ & $p$ & $\beta$ & $p$ & $\beta$ & $p$ \\
\hline MBP & 44 & 0.30 & 0.110 & 0.26 & 0.151 & 0.37 & 0.075 & 0.39 & 0.062 \\
CNPase & 50 & $\mathbf{0 . 3 8}$ & $\mathbf{0 . 0 2 2}$ & $\mathbf{0 . 3 6}$ & $\mathbf{0 . 0 2 9}$ & $\mathbf{0 . 4 9}$ & $\mathbf{0 . 0 0 5}$ & $\mathbf{0 . 4 9}$ & $\mathbf{0 . 0 0 5}$ \\
\hline
\end{tabular}

\section{Discussion}


The oxysterol $27-\mathrm{OH}$ is suggested to be the missing link between midlife hypercholesterolemia and increased risk of developing AD (2). Nonetheless, relatively little is known about the effects $27-\mathrm{OH}$ poses on the brain - especially on oligodendrocytes and myelination. In our study, we observed that a physiologically relevant concentration of $27-0 \mathrm{H}$ induces cell death in primary oligodendrocytes which is in line with a previous study in an astrocytic cell model (58). In another study $27-0 \mathrm{H}$ did not cause cell death in a murine oligodendrocyte cell line (59) which is in compliance to our finding that immortalized cells (HOG) were resistant to $27-\mathrm{OH}$ toxicity at relevant concentrations. The main result in this study was the noteworthy induction of OPC maturation by $27-\mathrm{OH}$. We postulate that the significant reduction in OPCs in the 3D-cell model is mainly a result of maturation rather than of an extensive OPC cell death as the total number of oligodendrocytes was not altered and there was additionally a modest increase in mature oligodendrocytes. Oligodendrocytes of any differentiation stage are vulnerable to cytotoxicity but depending on the agent there might be differences in the overall effect between OPCs and mature oligodendrocytes, given their different gene expression profile (60). As the cells were treated only once, the long-term effect observed is quite outstanding as $27-\mathrm{OH}$ is rather quickly metabolised in about two hours (57). In some studies, $A \beta$ has been demonstrated to cause a similar effect in OPCs, implying that OPCs are vulnerable and an induction of their differentiation resulting in impaired proliferation capabilities may play a role in changes in myelin integrity observed in $A D(39,41-43)$. The remodelling capacity is essential, as myelination continues long into adulthood (25). Induction of OPC maturation into myelinating oligodendrocytes is desired in demyelinating diseases, but the timing of maturation must be adjusted to the need. This suggests that hypercholesterolemia and oxysterol related OPC maturation may in fact impair the ability of proper and timely remyelination when needed. Our results support the findings of Sim and colleagues (45) who detected a PPARy-induced OPC maturation after simvastatin or pravastatin treatment. Due to the comparable impact on cholesterol metabolism and synthesis between statins and excess $27-\mathrm{OH}$, it would be of future interest to elucidate whether the molecular mechanisms behind the oligodendroglial effects of these agents are corresponding. To summarise, we hypothesise that a loss of proliferating OPCs due to chronic exposure to 27-OH could impact the remyelinating capacity. As oxysterols and $27-\mathrm{OH}$ in particular, are known to affect also other cell types in the brain $(18,21)$, the possibility that $27-\mathrm{OH}$ would indirectly influence OPCs cannot be excluded. We did not see a decrease in the OPC marker PDGFRa in old Cyp27Tg mice suggesting that in vivo, there may be compensatory mechanisms maintaining the OPC population. OPCs are nonetheless not spared from impacts that come along with ageing, and old OPCs do not respond similarly to maturation signals as young OPCs do (61).

Our findings of increased MBP expression in transgenic mice with elevated 27-OH concentrations support the rationale of $27-\mathrm{OH}$ promoting oligodendrocyte maturation. Many factors are essential and ratelimiting for myelin formation, for example, cholesterol, CNPase, and MBP (62-64). However, it would seem that the myelin composition requires clear stability to function properly. Not only reduced, but even excess levels of MBP result in impaired myelin sheath formation (65). Furthermore, the interplay between a proper lipid composition and protein profile is salient for a functional myelin sheath (66). $27-\mathrm{OH}$ accumulates in the lipid rafts of oligodendrocytes (59), which may result in altered membrane properties 
(67). In the myelin enriched fractions of Cyp27Tg and $\mathrm{Tg}$ - mice the protein level of MBP is similar in both strains, yet the PLP and MOG levels are attenuated in Cyp27Tg brains. Lindner and colleagues (68) demonstrate in their study how the levels of MBP, CNPase, PLP, and MOG behave during de- and remyelination. Quantities of these proteins decrease significantly during demyelination, but while MBP, CNPase, and PLP recover their levels during remyelination quickly, original levels of MOG are not reached during the observed time. Their results imply that expression of MOG could be a marker of late myelinating oligodendrocytes and could give a hint of the functionality of myelin. We propose that the imbalance we observe between the protein levels in our study could involve alterations in myelin integrity caused by chronic exposure to $27-\mathrm{OH}$ or long-term effects of high $27-\mathrm{OH}$ exposure during life, for instance from hypercholesterolemia. More studies should be conducted for a more precise understanding of the effects that $27-\mathrm{OH}$ poses on myelin structure, formation, and how $27-\mathrm{OH}$ interacts with the multifactorial neurodegenerative pathways, including proteinopathies, glutamate excitotoxicity, hyperexcitability, autophagy saturation.

Male Cyp27Tg mice have previously been reported to exhibit deficits in memory at the age of 8-9 months and for example impaired neuronal morphology and function $(18,19)$. A similar effect of 27-OH overload on memory has been reported in rats (69). In mice modelling cerebrovascular pathology, high-cholesteroldiet induced white matter changes and reduced numbers of immature oligodendrocytes, accompanied by cognitive deficits (7). In our study, female Cyp27Tg mice did demonstrate impairment in learning in MWM at the age of 8 months, indicating no sex differences in the effect of $27-\mathrm{OH}$ in spatial learning. In Y-maze and FC we were unable to detect significant differences; however, the control group consisted of only five $\mathrm{Tg}$ - mice reducing the power to detect small differences. As observed in previous studies, $27-\mathrm{OH}$ has a varying impact on different functions of the brain raging from morphological changes of neurons and reduced spine density in the hippocampus (18), decreased glucose uptake of neurons (19), induced inflammatory responses (20), to induced maturation of oligodendrocytes as observed in the current study. Plausible alterations in remodelling capacity of oligodendroglia and myelin structure may contribute to the impaired cognition of animals with excess levels of $27-\mathrm{OH}$. At the age of 8 months, there was no difference in oligodendrocyte maturation, as there were similar numbers of immature PDGFRa positive and mature $\mathrm{CC} 1$ positive cells. Nor was there any major difference in the extent of myelination as observed with LFB staining. Nevertheless, the significant increase of MBP production in corpus callosum and imbalance in other myelin proteins as detected in myelin enriched fractions may imply that small alterations in white matter composition may contribute to the attenuated cognitive performance. It is to be emphasised, however, that our results only represent a snapshot in the lifespan of female Cyp27Tg mice, and therefore we are unable to draw conclusions on how these alterations have been generated and what is to come along when the mice age. Moreover, some cognitive dysfunction can only be observed in paradigms testing energy-intensive plasticity, such as hippocampal long-term potentiation, which is aberrant in Cyp27Tg mice at 2 months of age (70).

Myelin proteins are released into CSF when the white matter is damaged (71). In post-mortem brains of AD patients, depletion of cholesterol, MBP, and CNPase have been detected (72). Moreover, substantially higher CSF concentrations of $27-0 \mathrm{H}$ are present in brain-damaging diseases, including demyelinating 
polyneuropathy and $\operatorname{AD}(15,16)$, emphasising a plausible connection of this oxysterol in CSF and demyelination and/or neuronal damage. Increasing CSF 27-OH levels have previously been associated with WMH burden in an AD-like cohort (73), and some cases of spastic paraplegia type 5 - a disease that results in elevated 27-OH levels due to mutations in CYP7B1 gene that is responsible for catabolising excess $27-\mathrm{OH}$ - white matter abnormalities have been reported (74). In our study, we found a positive association between CNPase and 27-OH that was not dependent on AD pathology. However, already in the mid-nineties Braak and Braak reported that the Tau-related changes seen in AD follow the inverse pattern of myelinogenesis (31), and later it has been proven that even demyelination follows this same pattern $(32,75)$. Hence, there could be a possible association with the presence of neurofibrillary tangles and myelin lesions, which should be investigated in post-mortem brain in the future. Based on the available literature (76), we postulate that CNPase in CSF theoretically could be a marker for oligodendrocyte maturation. In this context, CNPase association to 27-OH may represent its role in oligodendrocyte maturation. However, our results should only be regarded as exploratory due to the small sample size and thus limited statistical power. These results should be verified in larger cohorts and preferably together with neuroimaging data.

\section{Conclusions}

Based on our findings, 27-OH affects oligodendrocytes in at least three ways: It stimulates maturation of OPCs into mature oligodendrocytes, alters protein levels in myelin, and induces cell death of oligodendrocytes. We discuss the possibility that these mechanisms may contribute to white matter changes and dementia resulting from hypercholesterolemia.

\section{Abbreviations}

24-OH 24S-hydroxycholesterol

27-OH 27-hydroxycholesterol

A $\beta$ Amyloid-beta

AD Alzheimer's disease

BBB Blood-brain barrier

CC1 Adenomatous polyposis coli clone 1

CNPase 2',3'-Cyclic-nucleotide 3'-phosphodiesterase

CNS Central nervous system

CSF Cerebrospinal fluid 
CT Computed tomography

CYP27A1 Human sterol 27-hydroxylase

Cyp27Tg Human sterol 27-hydroxylase overexpressing mice

DIV Days-in-vitro

FC Fear conditioning

HOG Human oligodendroglioma

IF Immunofluorescence

LFB Luxol fast blue

$\mathrm{MCl}$ Mild cognitive impairment

MBP Myelin basic protein

MMSE Mini Mental State Examination

MOG Myelin oligodendrocyte glycoprotein

MRI Magnetic resonance imaging

MWM Morris Water Maze

NGS Normal goat serum

Olig2 Oligodendrocyte transcription factor 2

OPC Oligodendrocyte progenitor cell

PDGFRa Platelet-derived growth factor receptor a

PLP Myelin proteolipid protein

p-Tau Phosphorylated tau

RAVLT Rey Auditory Verbal Learning Test

SCI Subjective cognitive impairment

$\mathrm{Tg}$ - Non-transgenic littermates of Cyp27Tg mice

$\mathrm{t}-$ Tau Total tau 
VaD Vascular dementia

WMH White matter hyperintensity

DECLARATIONS

\section{Declarations}

\section{Ethics approval and consent to participate}

All experimental procedures on mice were performed following the local national animal care and use guidelines of Sweden and Spain and approved by the Swedish Board of Agriculture and Ethics Committees of the University of the Basque Country (UPV/EHU) (ethical permit ID 4884/2019 and $M 20 / 2017 / 011$ ). All possible efforts were made to minimize the suffering and distress of the animals.

CSF samples from memory clinic patients were from the biobank and database GEDOC. All participants gave written informed consent and permissions from the Swedish Ethical Review Authority to conduct the research have been approved (2011/1987-31/4 and 2019-06056).

\section{Consent for publication}

Not applicable.

\section{Competing interests}

The authors have no competing interests to declare.

\section{Authors' contributions}

ACM, CM, EA and ASM designed the research project. VA, TQL, AGB, IB, SM, GT, MLL performed and analyzed experiments with input from AS, ACM, RLV, CM, MK, EA and ASM. VA drafted the first version of the manuscript with input from ASM, RLV and EA. All authors read, reviewed, edited, and approved the final manuscript.

\section{Acknowledgements}

The authors thank Makbule Sagici for technical expertise on mouse brain paraffinization and sectioning, Dr Cristina Parrado for preparing the myelin fractions and Fokion Spanos for helping with time-course 3D culture preparations. The behavioral studies were performed at the Animal Behavior Core Facility (ABCF) of Karolinska Institutet.

FUNDING 
This research was supported by the Swedish Research Council 2017-06105, Center for Innovative Medicine (CIMED) at Karolinska Institutet, Margareta af Ugglas foundation, Alzheimerfonden Sweden, Region Stockholm (ALF, NSV), Knut and Alice Wallenberg Foundation, Stiftelsen Stockholms sjukhem, Konung Gustaf V:s och Drottning Victorias Frimurarstiftelse, Gun och Bertil Stohnes Stiftelse, the Karolinska Institutet fund for geriatric research, Stiftelsen Gamla Tjänarinnor, European Research Council grant 804371, Academy of Finland, the Basque Government (IT1203-19; PIBA_2020_1_0012; fellowship to TQL), CIBERNED, and MICINN (PID2019-108465RB-I00; fellowship to AGB FPU17/04822.)

\section{AVAILABILITY OF DATA AND MATERIALS}

The data generated and/or analysed during the current study are not publicly available but are available from the corresponding author on reasonable request.

\section{References}

1. Lisko I, Kulmala J, Annetorp M, Ngandu T, Mangialasche F, Kivipelto M. How can dementia and disability be prevented in older adults: where are we today and where are we going? $\mathrm{J}$ Intern Med. 2020.

2. Anstey KJ, Ashby-Mitchell K, Peters R. Updating the evidence on the association between serum cholesterol and risk of late-life dementia: Review and meta-analysis. Journal of Alzheimer's Disease. 2017; Vol. 56:215-28.

3. Wingo TS, Cutler DJ, Wingo AP, Le NA, Rabinovici GD, Miller BL, et al. Association of Early-Onset Alzheimer Disease with Elevated Low-Density Lipoprotein Cholesterol Levels and Rare Genetic Coding Variants of APOB. JAMA Neurol. 2019 Jul 1;76(7):809-17.

4. Appleton JP, Scutt P, Sprigg N, Bath PM. Hypercholesterolaemia and vascular dementia. Clin Sci. 2017 Jul 15;131(14):1561-78.

5. Zambón D, Quintana M, Mata P, Alonso R, Benavent J, Cruz-Sánchez F, et al. Higher incidence of mild cognitive impairment in familial hypercholesterolemia. Am J Med. 2010;123(3):267-74.

6. Jurevics H, Morell P. Cholesterol for Synthesis of Myelin Is Made Locally, Not Imported into Brain. J Neurochem. 1995;64(2):895-901.

7. Tong XK, Trigiani LJ, Hamel E. High cholesterol triggers white matter alterations and cognitive deficits in a mouse model of cerebrovascular disease: benefits of simvastatin. Cell Death Dis. 2019 Feb 1;10(2):89.

8. de Bem AF, Krolow R, Farias HR, de Rezende VL, Gelain DP, Moreira JCF, et al. Animal Models of Metabolic Disorders in the Study of Neurodegenerative Diseases: An Overview. Front Neurosci. 2021 Jan;18:14:604150.

9. Heverin M, Meaney S, Lütjohann D, Diczfalusy U, Wahren J, Björkhem I. Crossing the barrier: net flux of 27-hydroxycholesterol into the human brain. J Lipid Res. 2005;46(5):1047-52. 
10. Björkhem I, Lütjohann D, Diczfalusy U, Ståhle L, Ahlborg G, Wahren J. Cholesterol homeostasis in human brain: turnover of 24S-hydroxycholesterol and evidence for a cerebral origin of most of this oxysterol in the circulation. J Lipid Res. 1998;39(8):1594-600.

11. Björkhem I, Heverin M, Leoni V, Meaney S, Diczfalusy U. Oxysterols and Alzheimer's disease. Acta Neurol Scand. 2006;Vol. 114:43-9.

12. Loera-Valencia R, Goikolea J, Parrado-Fernandez C, Merino-Serrais P, Maioli S. Alterations in cholesterol metabolism as a risk factor for developing Alzheimer's disease: Potential novel targets for treatment. Vol. 190, Journal of Steroid Biochemistry and Molecular Biology. 2019. p. 104-14.

13. Uhlén M, Fagerberg L, Hallström BM, Lindskog C, Oksvold P, Mardinoglu A, et al. Tissue-based map of the human proteome. Science (80-). 2015 Jan 23;347(6220):1260419-1260419.

14. Heverin M, Bogdanovic N, Lütjohann D, Bayer T, Pikuleva I, Bretillon L, et al. Changes in the levels of cerebral and extracerebral sterols in the brain of patients with Alzheimer's disease. J Lipid Res. 2004 Jan;45(1):186-93.

15. Mateos L, Ismail M-A-M, Gil-Bea F-J, Leoni V, Winblad B, Björkhem I, et al. Upregulation of Brain Renin Angiotensin System by 27-Hydroxycholesterol in Alzheimer's Disease. J Alzheimer's Dis. 2011 May 30;24(4):669-79.

16. Leoni V, Masterman T, Mousavi FS, Wretlind B, Wahlund LO, Diczfalusy U, et al. Diagnostic use of cerebral and extracerebral oxysterols. Clin Chem Lab Med. 2004;42(2):186-91.

17. Sandebring-Matton A, Goikolea J, Björkhem I, Paternain L, Kemppainen N, Laatikainen T, et al. 27hydroxycholesterol, cognition and brain imaging markers in the FINGER randomized controlled trial. Alzheimer's Res Ther. 2021.

18. Merino-Serrais P, Loera-Valencia R, Rodriguez-Rodriguez P, Parrado-Fernandez C, Ismail MA, Maioli S, et al. 27-Hydroxycholesterol Induces Aberrant Morphology and Synaptic Dysfunction in Hippocampal Neurons. Cereb Cortex. 2019;29(1):429-46.

19. Ismail M-A-M, Mateos L, Maioli S, Merino-Serrais P, Ali Z, Lodeiro M, et al. 27-Hydroxycholesterol impairs neuronal glucose uptake through an IRAP/GLUT4 system dysregulation. J Exp Med. 2017;214(3):699-717.

20. Testa G, Gamba P, Badilli U, Gargiulo S, Maina M. Loading into Nanoparticles Improves Quercetin's Efficacy in Preventing Neuroinflammation Induced by Oxysterols. PLoS One. 2014;9(5):e96795.

21. Staurenghi E, Cerrato V, Gamba P, Testa G, Giannelli S, Leoni V, et al. Oxysterols present in Alzheimer's disease brain induce synaptotoxicity by activating astrocytes: A major role for lipocalin-2. Redox Biol. 2021 Feb 1;39:101837.

22. Bartzokis G. Alzheimer's disease as homeostatic responses to age-related myelin breakdown. Neurobiol Aging. 2011;32(8):1341-71.

23. Nasrabady SE, Rizvi B, Goldman JE, Brickman AM. White matter changes in Alzheimer's disease: a focus on myelin and oligodendrocytes. Acta Neuropathol Commun. 2018;6(1):22.

24. Kavroulakis E, Simos PG, Kalaitzakis G, Maris TG, Karageorgou D, Zaganas I, et al. Myelin content changes in probable Alzheimer's disease and mild cognitive impairment: Associations with age and 
severity of neuropsychiatric impairment. J Magn Reson Imaging. 2018 May 1;47(5):1359-72.

25. Bartzokis G, Cummings JL, Sultzer D, Henderson VW, Nuechterlein KH, Mintz J. White matter structural integrity in healthy aging adults and patients with Alzheimer disease: A magnetic resonance imaging study. Arch Neurol. 2003 Mar 1;60(3):393-8.

26. de Schipper LJ, Hafkemeijer A, Bouts MJRJ, van der Grond J, Marinus J, Henselmans JML, et al. Ageand disease-related cerebral white matter changes in patients with Parkinson's disease. Neurobiol Aging. 2019 Aug 1;80:203-9.

27. Shaffer JJ, Ghayoor A, Long JD, Kim REY, Lourens S, O'Donnell LJ, et al. Longitudinal diffusion changes in prodromal and early HD: Evidence of white-matter tract deterioration. Hum Brain Mapp. 2017 Mar 1;38(3):1460-77.

28. Ihara M, Polvikoski TM, Hall R, Slade JY, Perry RH, Oakley AE, et al. Quantification of myelin loss in frontal lobe white matter in vascular dementia, Alzheimer's disease, and dementia with Lewy bodies. Acta Neuropathol. 2010 May;119(5):579-89.

29. Wardlaw JM, Valdés Hernández MC, Muñoz-Maniega S. What are white matter hyperintensities made of? Relevance to vascular cognitive impairment. Vol. 4: Journal of the American Heart Association. Wiley-Blackwell; 2015. p. e001140.

30. Gargiulo S, Rossin D, Testa G, Gamba P, Staurenghi E, Biasi F, et al. Up-regulation of COX-2 and mPGES-1 by 27-hydroxycholesterol and 4-hydroxynonenal: A crucial role in atherosclerotic plaque instability. Free Radic Biol Med. 2018 Dec;1:129:354-63.

31. Braak H, Braak E. Development of Alzheimer-related neurofibrillary changes in the neocortex inversely recapitulates cortical myelogenesis. Acta Neuropathol. 1996 Jul;15(2):197-201. 92(.

32. Benitez A, Fieremans E, Jensen JH, Falangola MF, Tabesh A, Ferris SH, et al. White matter tract integrity metrics reflect the vulnerability of late-myelinating tracts in Alzheimer's disease. Neurolmage Clin. 2014 Jan;1:4:64-71.

33. Marner L, Nyengaard JR, Tang Y, Pakkenberg B. Marked loss of myelinated nerve fibers in the human brain with age. J Comp Neurol. 2003 Jul;21(2):144-52. 462(.

34. Lee S, Viqar F, Zimmerman ME, Narkhede A, Tosto G, Benzinger TLS, et al. White matter hyperintensities are a core feature of Alzheimer's disease: Evidence from the dominantly inherited Alzheimer network. Ann Neurol. 2016 Jun 1;79(6):929-39.

35. Dean DC, Hurley SA, Kecskemeti SR, O'Grady JP, Canda C, Davenport-Sis NJ, et al. Association of amyloid pathology with myelin alteration in preclinical Alzheimer disease. JAMA Neurol. 2017 Jan 1;74(1):41-9.

36. Franklin RJM, Ffrench-Constant C. Remyelination in the CNS: From biology to therapy. Nature Reviews Neuroscience Nat Rev Neurosci. 2008;Vol. 9:839-55.

37. Sim FJ, Zhao C, Penderis J, Franklin RJM. The Age-Related Decrease in CNS Remyelination Efficiency Is Attributable to an Impairment of Both Oligodendrocyte Progenitor Recruitment and Differentiation. J Neurosci. 2002 Apr 1;22(7):2451-9. 
38. French HM, Reid M, Mamontov P, Simmons RA, Grinspan JB. Oxidative stress disrupts oligodendrocyte maturation. J Neurosci Res. 2009 Nov 1;87(14):3076-87.

39. Zhang P, Kishimoto Y, Grammatikakis I, Gottimukkala K, Cutler RG, Zhang S, et al. Senolytic therapy alleviates $A \beta$-associated oligodendrocyte progenitor cell senescence and cognitive deficits in an Alzheimer's disease model. Nat Neurosci. 2019 May 1;22(5):719-28.

40. Spitzer SO, Sitnikov S, Kamen Y, Evans KA, Kronenberg-Versteeg D, Dietmann S, et al. Oligodendrocyte Progenitor Cells Become Regionally Diverse and Heterogeneous with Age. Neuron. 2019 Feb 6;101(3):459-471.e5.

41. Quintela-López T, Ortiz-Sanz C, Serrano-Regal MP, Gaminde-Blasco A, Valero J, Baleriola J, et al. A $\beta$ oligomers promote oligodendrocyte differentiation and maturation via integrin $\beta 1$ and Fyn kinase signaling. Cell Death Dis. 2019 Jun 1;10(6):1-16.

42. Behrendt G, Baer K, Buffo A, Curtis MA, Faull RL, Rees MI, et al. Dynamic changes in myelin aberrations and oligodendrocyte generation in chronic amyloidosis in mice and men. Glia. 2013 Feb 1;61(2):273-86.

43. Vanzulli I, Papanikolaou M, De-La-Rocha IC, Pieropan F, Rivera AD, Gomez-Nicola D, et al. Disruption of oligodendrocyte progenitor cells is an early sign of pathology in the triple transgenic mouse model of Alzheimer's disease. Neurobiol Aging. 2020 Oct 1;94:130-9.

44. Chacon-De La Rocha I, Fryatt G, Rivera A, Verkhratsky A, Raineteau O, Gomez-Nicola D, et al. Accelerated dystrophy and decay of oligodendrocyte precursor cells in the APP/PS1 model of Alzheimer's-like pathology. Front Cell Neurosci. 2020;14.

45. Sim FJ, Lang JK, Ali TA, Roy NS, Vates GE, Pilcher WH, et al. Statin treatment of adult human glial progenitors induces PPARY-mediated oligodendrocytic differentiation. Glia. 2008 Jul;56(9):954-62.

46. Ali Z, Heverin M, Olin M, Acimovic J, Lövgren-Sandblom A, Shafaati M, et al. On the regulatory role of side-chain hydroxylated oxysterols in the brain. Lessons from CYP27A1 transgenic and Cyp27a1(-/-) mice. J Lipid Res. 2013 Apr;54(4):1033-43.

47. Meir K, Kitsberg D, Alkalay I, Szafer F, Rosen H, Shpitzen S, et al. Human sterol 27-hydroxylase (CYP27) overexpressor transgenic mouse model. Evidence against 27-hydroxycholesterol as a critical regulator of cholesterol homeostasis. J Biol Chem. 2002 Sep 13;277(37):34036-41.

48. Post GR, Dawson G. Characterization of a cell line derived from a human oligodendroglioma. Mol Chem Neuropathol. 1992 Jun;16(3):303-17.

49. Buntinx M, Vanderlocht J, Hellings N, Vandenabeele F, Lambrichts I, Raus J, et al. Characterization of three human oligodendroglial cell lines as a model to study oligodendrocyte injury: Morphology and oligodendrocyte-specific gene expression. J Neurocytol. 2003 Jan;32(1):25-38.

50. Barres BA, Hart IK, Coles HSR, Burne JF, Voyvodic JT, Richardson WD, et al. Cell death and control of cell survival in the oligodendrocyte lineage. Cell. 1992 Jul 10;70(1):31-46.

51. Maioli S, Båvner A, Ali Z, Heverin M, Ismail MAM, Puerta E, et al. Is It Possible to Improve Memory Function by Upregulation of the Cholesterol 24S-Hydroxylase (CYP46A1) in the Brain? PLoS One. 2013 Jul 16;8(7):e68534. 
52. Eroli F, Johnell K, Leal ML, Adamo C, Hilmer S, Wastesson JW, et al. Chronic polypharmacy impairs explorative behavior and reduces synaptic functions in young adult mice. Aging. 2020 Jun;15(11):10147-61. 12(.

53. Schindelin J, Arganda-Carreras I, Frise E, Kaynig V, Longair M, Pietzsch T, et al. Fiji: An open-source platform for biological-image analysis. Nat Methods. 2012 Jul;28(7):676-82. 9(.

54. Underhill HR, Rostomily RC, Mikheev AM, Yuan C, Yarnykh VL. Fast bound pool fraction imaging of the in vivo rat brain: Association with myelin content and validation in the $\mathrm{C} 6$ glioma model. Neuroimage. 2011 Feb 1;54(3):2052-65.

55. Khodanovich MY, Sorokina IV, Glazacheva VY, Akulov AE, Nemirovich-Danchenko NM, Romashchenko AV, et al. Histological validation of fast macromolecular proton fraction mapping as a quantitative myelin imaging method in the cuprizone demyelination model. Sci Rep. 2017;7:46686.

56. Dzeletovic S, Breuer O, Lund E, Diczfalusy U. Determination of cholesterol oxidation products in human plasma by isotope dilution-mass spectrometry. Anal Biochem. 1995;225(1):73-80.

57. Mateos L, Ismail MAM, Gil-Bea FJ, Schüle R, Schöls L, Heverin M, et al. Side chain-oxidized oxysterols regulate the brain renin-angiotensin system through a liver $X$ receptor-dependent mechanism. J Biol Chem. 2011;286(29):25574-85.

58. An Y, Zhang D-D, Yu H-L, Ma W-W, Lu Y-H, Liu Q-R, et al. 27-Hydroxycholesterol regulates cholesterol synthesis and transport in C6 glioma cells. Neurotoxicology. 2017 Mar;1:59:88-97.

59. Ragot K, Mackrill JJ, Zarrouk A, Nury T, Aires V, Jacquin A, et al. Absence of correlation between oxysterol accumulation in lipid raft microdomains, calcium increase, and apoptosis induction on 158N murine oligodendrocytes. Biochem Pharmacol. 2013;86(1):67-79.

60. Kim JY, Kim JH, Kim YD, Seo JH. High vulnerability of oligodendrocytes to oxidative stress induced by ultrafine urban particles. Antioxidants. 2021 Jan 1;10(1):4.

61. Neumann B, Baror R, Zhao C, Segel M, Dietmann S, Rawji KS, et al. Metformin Restores CNS Remyelination Capacity by Rejuvenating Aged Stem Cells. Cell Stem Cell. 2019 Oct 3;25(4):485.

62. Saher G, Brügger B, Lappe-Siefke C, Möbius W, Tozawa RI, Wehr MC, et al. High cholesterol level is essential for myelin membrane growth. Nat Neurosci. 2005 Apr 27;8(4):468-75.

63. Lappe-Siefke C, Goebbels S, Gravel M, Nicksch E, Lee J, Braun PE, et al. Disruption of Cnp1 uncouples oligodendroglial functions in axonal support and myelination. Nat Genet. 2003 Mar $1 ; 33(3): 366-74$.

64. Popko B, Puckett C, Lai E, Shine HD, Readhead C, Takahashi N, et al. Myelin deficient mice: Expression of myelin basic protein and generation of mice with varying levels of myelin. Cell. 1987 Feb 27;48(4):713-21.

65. Min Y, Kristiansen K, Boggs JM, Husted C, Zasadzinski JA, Israelachvili J. Interaction forces and adhesion of supported myelin lipid bilayers modulated by myelin basic protein. Proc Natl Acad Sci U S A. 2009 Mar;3(9):3154-9. 106(.

66. Krugmann B, Radulescu A, Appavou MS, Koutsioubas A, Stingaciu LR, Dulle M, et al. Membrane stiffness and myelin basic protein binding strength as molecular origin of multiple sclerosis. Sci Rep. 
2020 Dec 1;10(1):16691.

67. Olżyńska A, Kulig W, Mikkolainen H, Czerniak T, Jurkiewicz P, Cwiklik L, et al. Tail-Oxidized Cholesterol Enhances Membrane Permeability for Small Solutes. Langmuir. 2020 Sep 8;36(35):10438-47.

68. Lindner M, Heine S, Haastert K, Garde N, Fokuhl J, Linsmeier F, et al. Sequential myelin protein expression during remyelination reveals fast and efficient repair after central nervous system demyelination. Neuropathol Appl Neurobiol. 2008 Feb;34(1):105-14.

69. Zhang DD, Yu HL, Ma WW, Liu QR, Han J, Wang H, et al. 27-Hydroxycholesterol contributes to disruptive effects on learning and memory by modulating cholesterol metabolism in the rat brain. Neuroscience. 2015 Aug 6;300:163-73.

70. Loera-Valencia R, Vazquez-Juarez E, Muñoz A, Gerenu G, Gómez-Galán M, Lindskog M, et al. High levels of 27-hydroxycholesterol results in synaptic plasticity alterations in the hippocampus. Sci Rep. 2021 Dec 1;11(1):3736.

71. Sellebjerg F, Börnsen L, Ammitzbøll C, Nielsen JE, Vinther-Jensen T, Hjermind LE, et al. Defining active progressive multiple sclerosis. Mult Scler. 2017 Nov 1;23(13):1727-35.

72. Roher AE, Weiss N, Kokjohn TA, Kuo YM, Kalback W, Anthony J, et al. Increased A $\beta$ peptides and reduced cholesterol and myelin proteins characterize white matter degeneration in Alzheimer's disease. Biochemistry. 2002 Sep 17;41(37):11080-90.

73. Besga A, Cedazo-Minguez A, Kåreholt I, Solomon A, Björkhem I, Winblad B, et al. Differences in brain cholesterol metabolism and insulin in two subgroups of patients with different CSF biomarkers but similar white matter lesions suggest different pathogenic mechanisms. Neurosci Lett. 2012 Feb;29(2):126. 510(.

74. Biancheri R, Ciccolella M, Rossi A, Tessa A, Cassandrini D, Minetti C, et al. White matter lesions in spastic paraplegia with mutations in SPG5/CYP7B1. Neuromuscul Disord. 2009 Jan;19(1):62-5.

75. Gao J, Cheung RT-F, Lee TMC, Chu L-W, Chan Y-S, Mak HK-F, et al. Possible Retrogenesis Observed with Fiber Tracking: An Anteroposterior Pattern of White Matter Disintegrity in Normal Aging and Alzheimer's Disease. J Alzheimer's Dis. 2011 Aug;26(1):47-58. 26(.

76. Rivers LE, Young KM, Rizzi M, Jamen F, Psachoulia K, Wade A, et al. PDGFRA/NG2 glia generate myelinating oligodendrocytes and piriform projection neurons in adult mice. Nat Neurosci. 2008 Dec;11(12):1392-401.

\section{Figures}


A

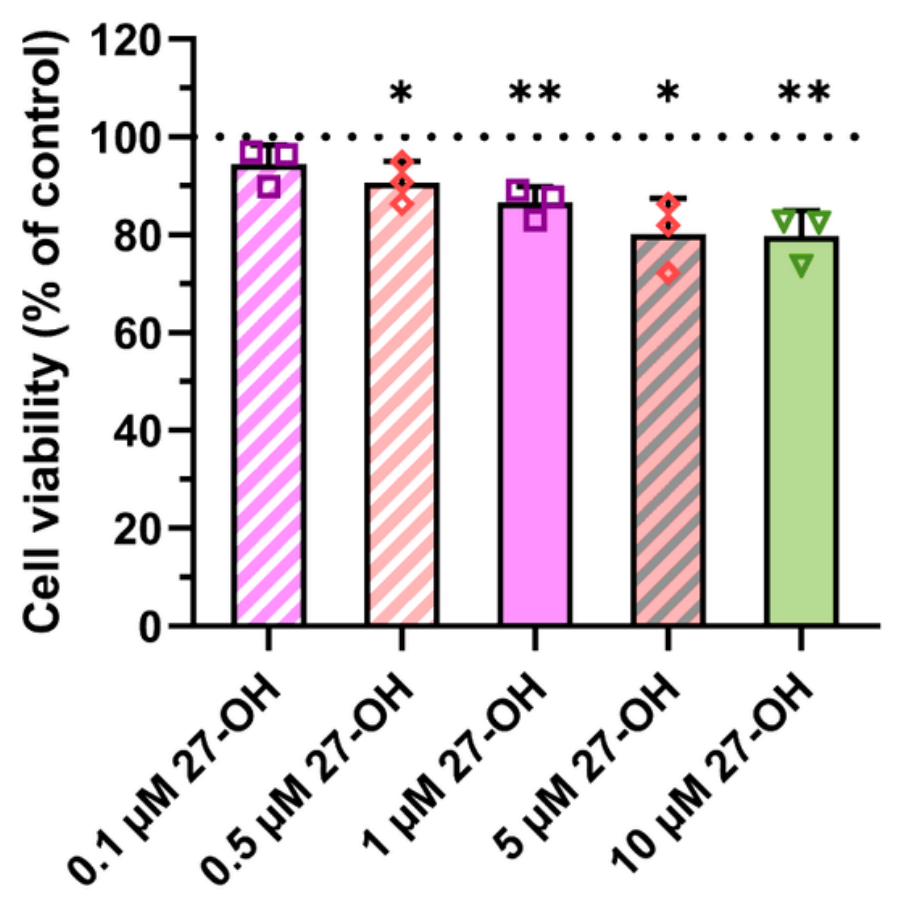

B

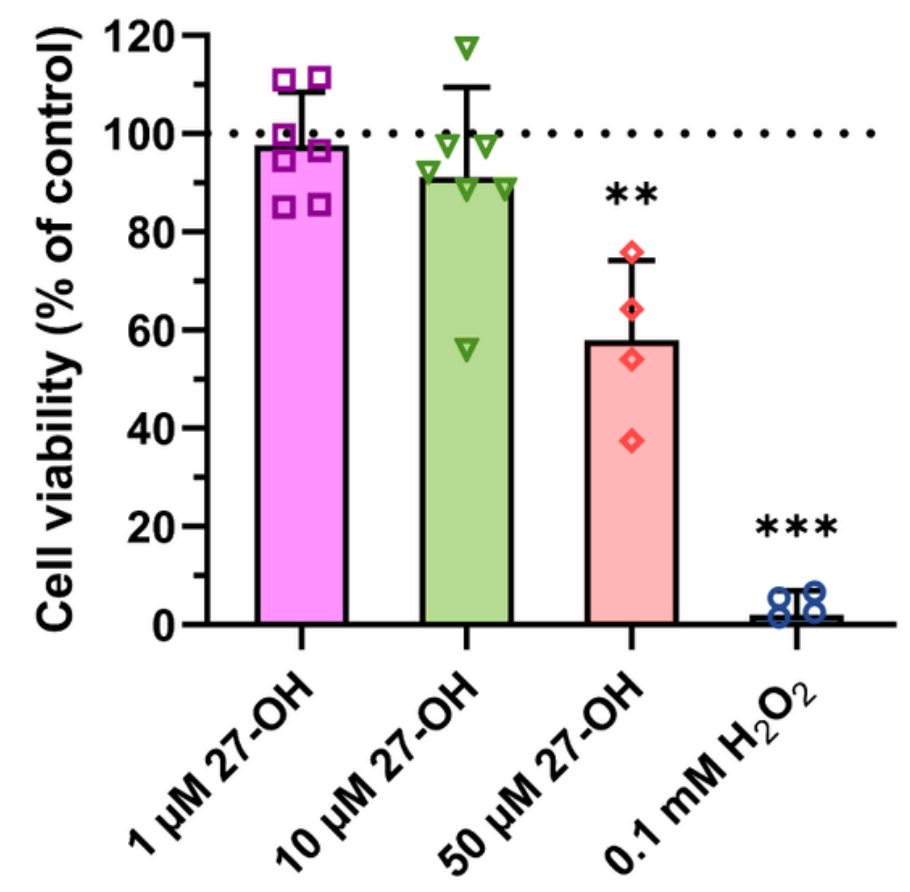

Figure 1

27-hydroxycholesterol $(27-\mathrm{OH})$ induces cell death in cultured oligodendroglia. Cell viability of $(\mathrm{A})$ primary oligodendrocytes derived from rat optic nerves and (B) human oligodendroglioma cell line was assessed with increasing concentrations of $27-\mathrm{OH}$. The dashed line represents control treatment. Unpaired Student's two-tailed t-test, all data presented as mean $\pm S D$, * $p<0.05$, ** $p<0.003$, $* \star \star p<0.0001$. 


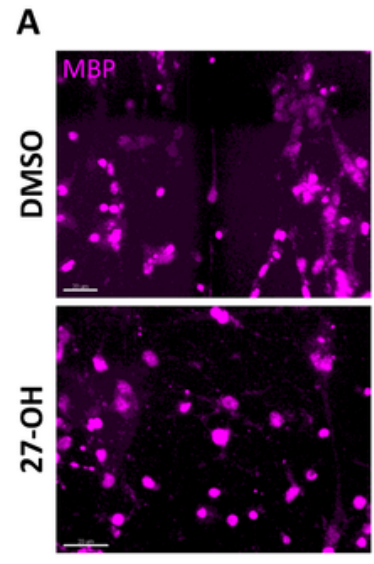

B

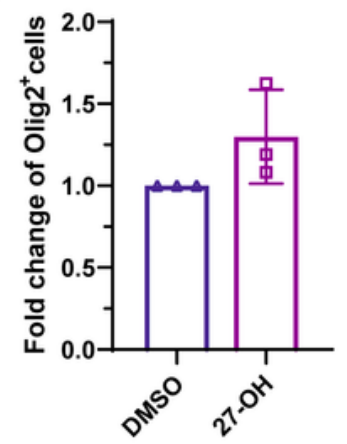

C

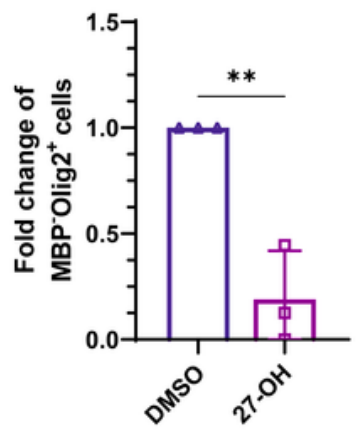

D

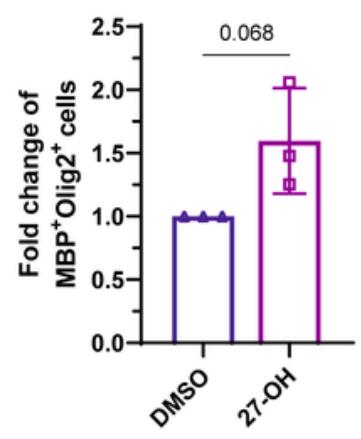

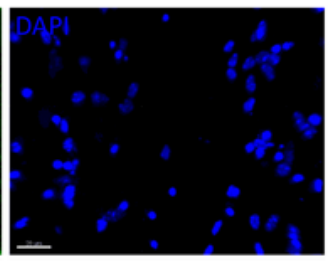
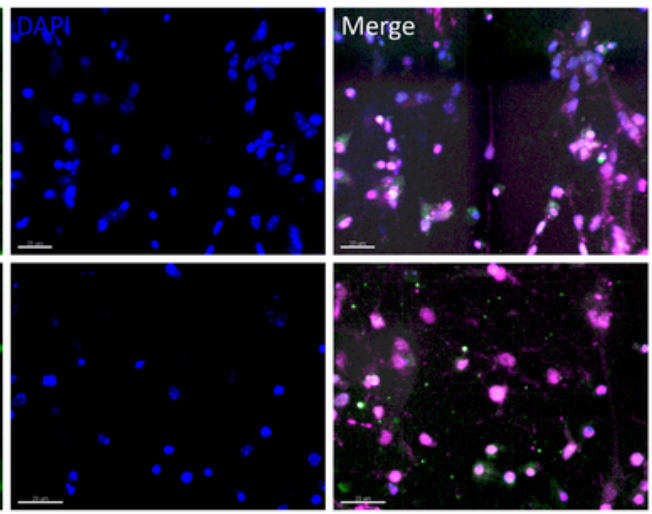

E

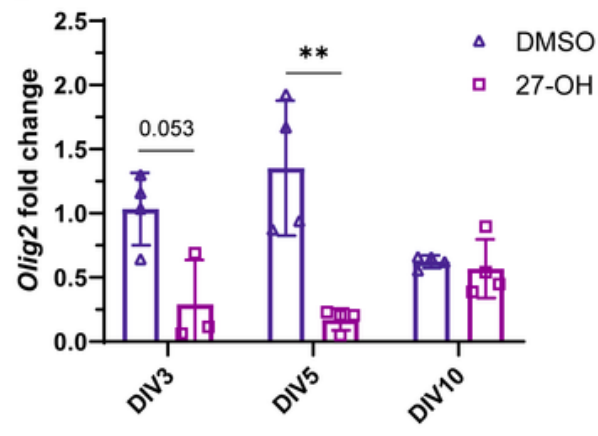

$\mathbf{F}$

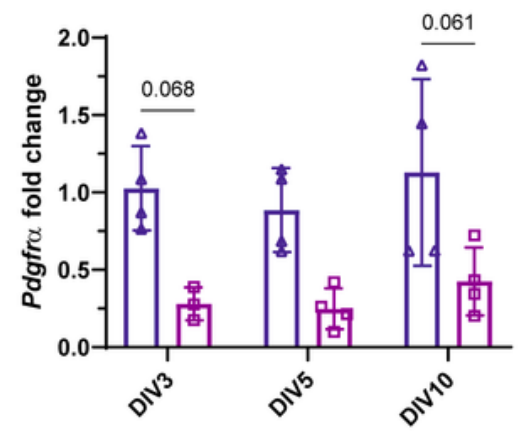

G

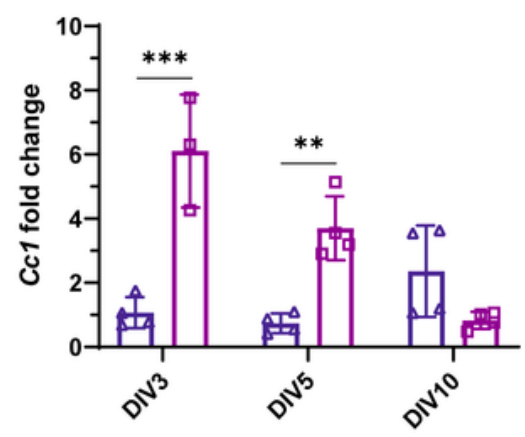

Figure 2

27-hydroxycholesterol (27-OH) stimulates maturation of oligodendrocytes in co-cultures. In 3D co-cultures set up from WT embryonic mouse hippocampus and cortex containing glial cells and neurons, effects of $1 \mu \mathrm{M}$ 27-OH treatment were investigated. In all experiments, cultures were treated at days-in-vitro (DIV) 1 with $27-\mathrm{OH}$ or vehicle (DMSO). (A) Immunofluorescence staining of 3D co-cultures at DIV20. MBP (myelin basic protein) labels mature oligodendrocytes and Olig2 (oligodendrocyte transcription factor 2) both 
immature and mature oligodendrocytes. Scale bars represent $20 \mu \mathrm{m}$. (B) When compared to the total number of cells in culture, the quantity of oligodendroglia (Olig2+) is similar between both treatments after DIV20. 27-OH induces a (C) significant decrease of immature oligodendrocytes (MBP-Olig2+) but does (D) not markedly alter the number of mature oligodendrocytes (MBP+Olig2+) when compared to the total number of cells in cultures at DIV20. In a time-course experiment, gene expression of (F) Pdgfra (platelet-derived growth factor receptor a, a marker for immature oligodendrocytes) and (G) Cc1 (adenomatous polyposis coli clone 1, a marker for mature oligodendrocytes) was investigated on DIV3, 5, and 10. To evaluate oligodendrocyte survival, gene expression of Olig2 was compared to the expression

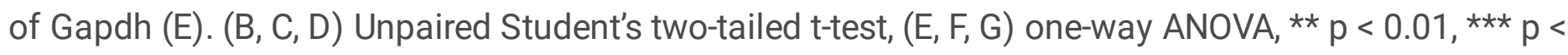
0.0001 , all data presented as mean \pm SD . 
A

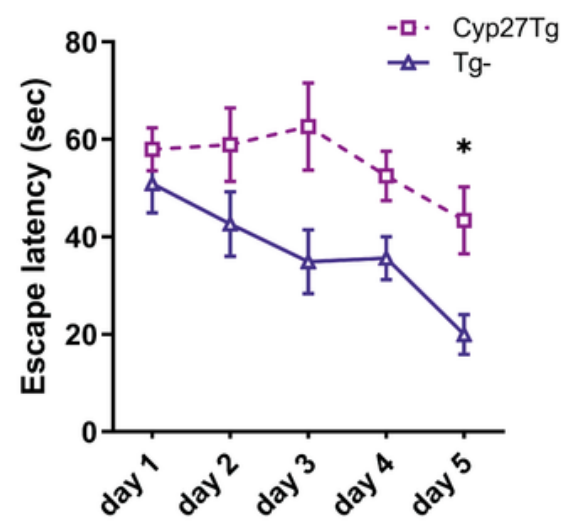

B

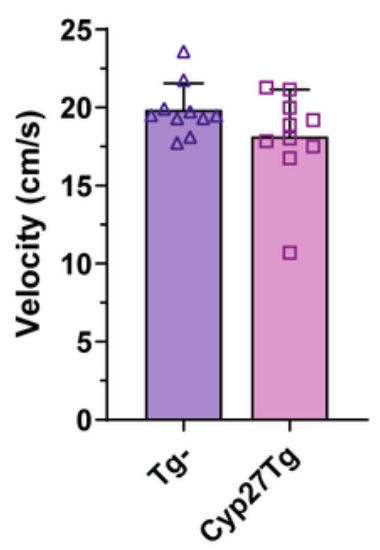

$\mathbf{E}$
C

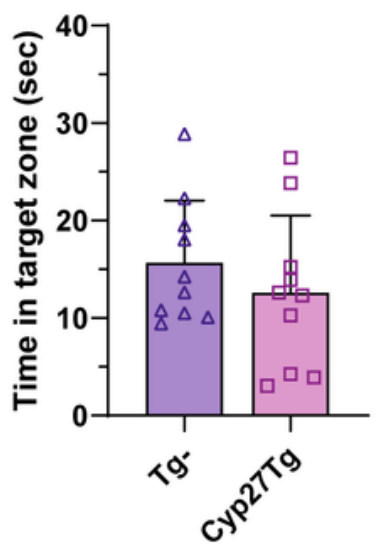

D

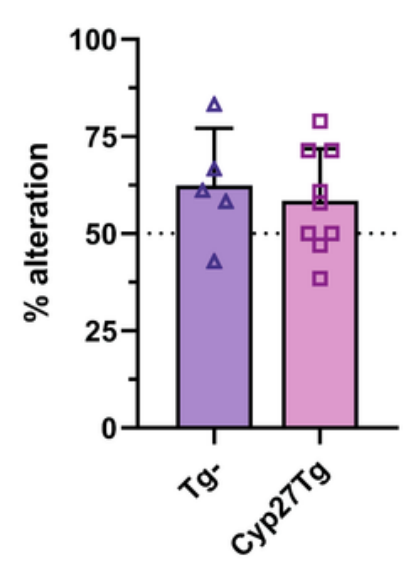

F

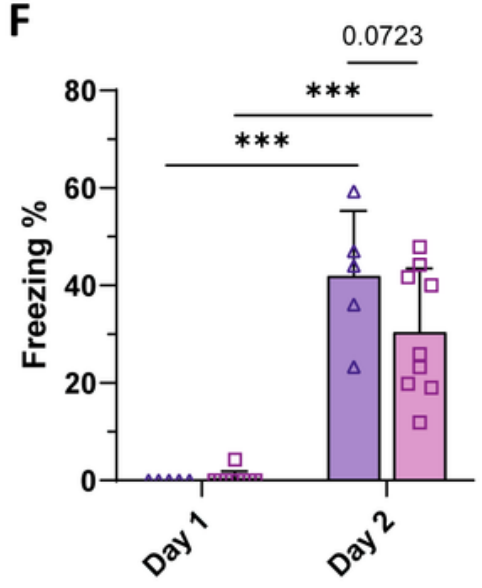

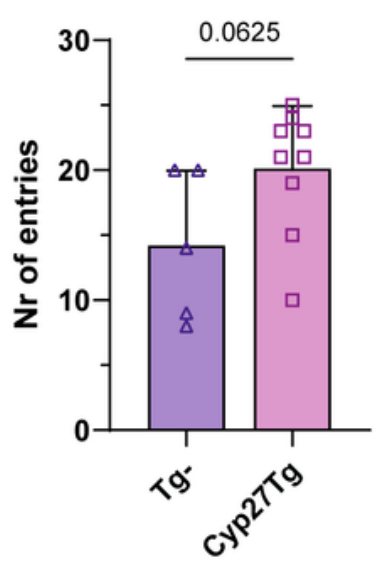

G

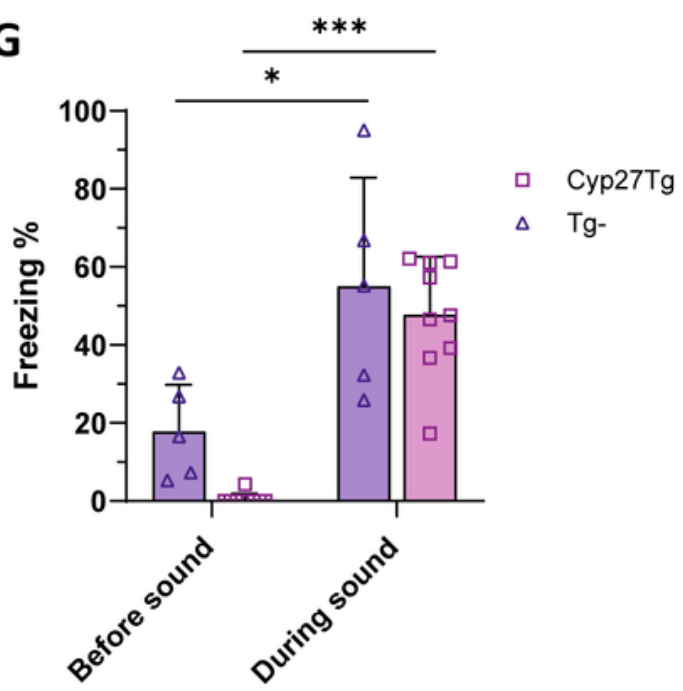

Figure 3

Female transgenic mice overexpressing human CYP27A1 (Cyp27Tg) have impaired spatial learning compared to controls. (A) In Morris Water Maze (MWM), the learning curve for Cyp27Tg mice is not as steep as for control mice during the five training days. (B) Velocity between strains is similar in MWM. On day six, mice performed the probe trial, where the platform was removed. (C) During the probe trial, Cyp27Tg and control mice spent an equal amount of time in the target zone. (D) in Y-maze, mice of both 
strains altered between the arms in similar amounts. (E) However, the number of entries was slightly increased in the Cyp27Tg group. Fear conditioning was performed on three consecutive days, where on day one mice were exposed to sound, following an electric shock. (F) On the second day, mice were exposed to the same context as on day one and freezing increased significantly in both strains. (G) On day three, mice were exposed to a new environment and the cue (sound) from the first day. Both strains demonstrated increased freezing during sound. $(A, F, G)$ Repeated-measures ANOVA, (B) Mann-Whitney U test two-tailed (C, D, E) unpaired Student's two-tailed t-test, * $p<0.05, * \star * p<0.0001$. All data presented as mean $\pm S D$, except $(A)$ is presented as mean \pm SEM.

A
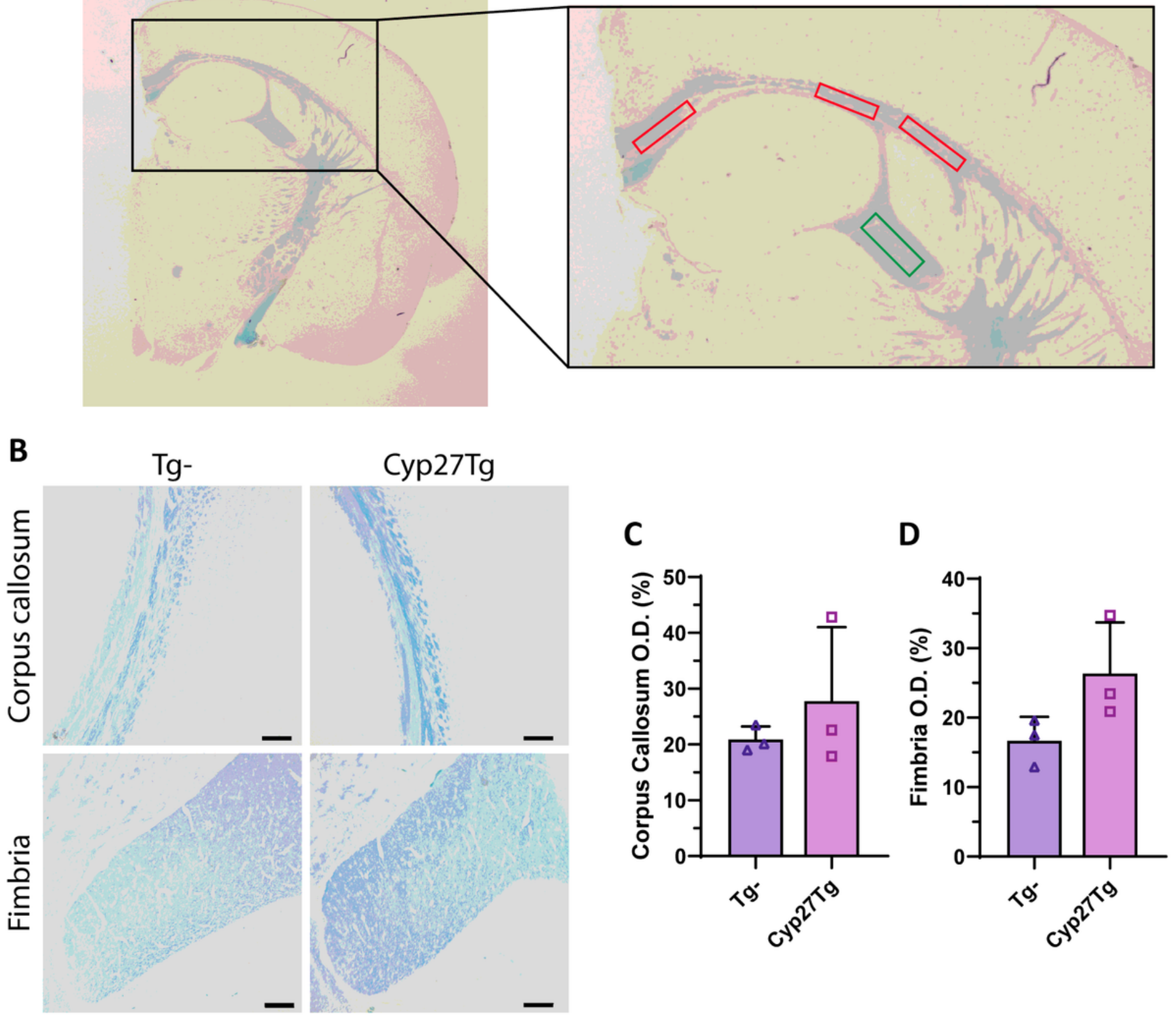

Figure 4 
Cyp27Tg mice have preserved overall myelin structure. (A) Brain sections were stained with Luxol fast blue (LFB), and areas of corpus callosum (average of the three red squares) and fimbria (one green square) were analysed for intensity differences between Cyp27Tg and Tg- mice. (B) Representative images of LFB stained corpus callosa and fimbriae. Scale bar represents $100 \mu \mathrm{m}$. Intensity difference in (C) corpus callosum and (D) fimbria. (C, D) Unpaired Student's two-tailed t-test, all data presented as mean \pm SD.
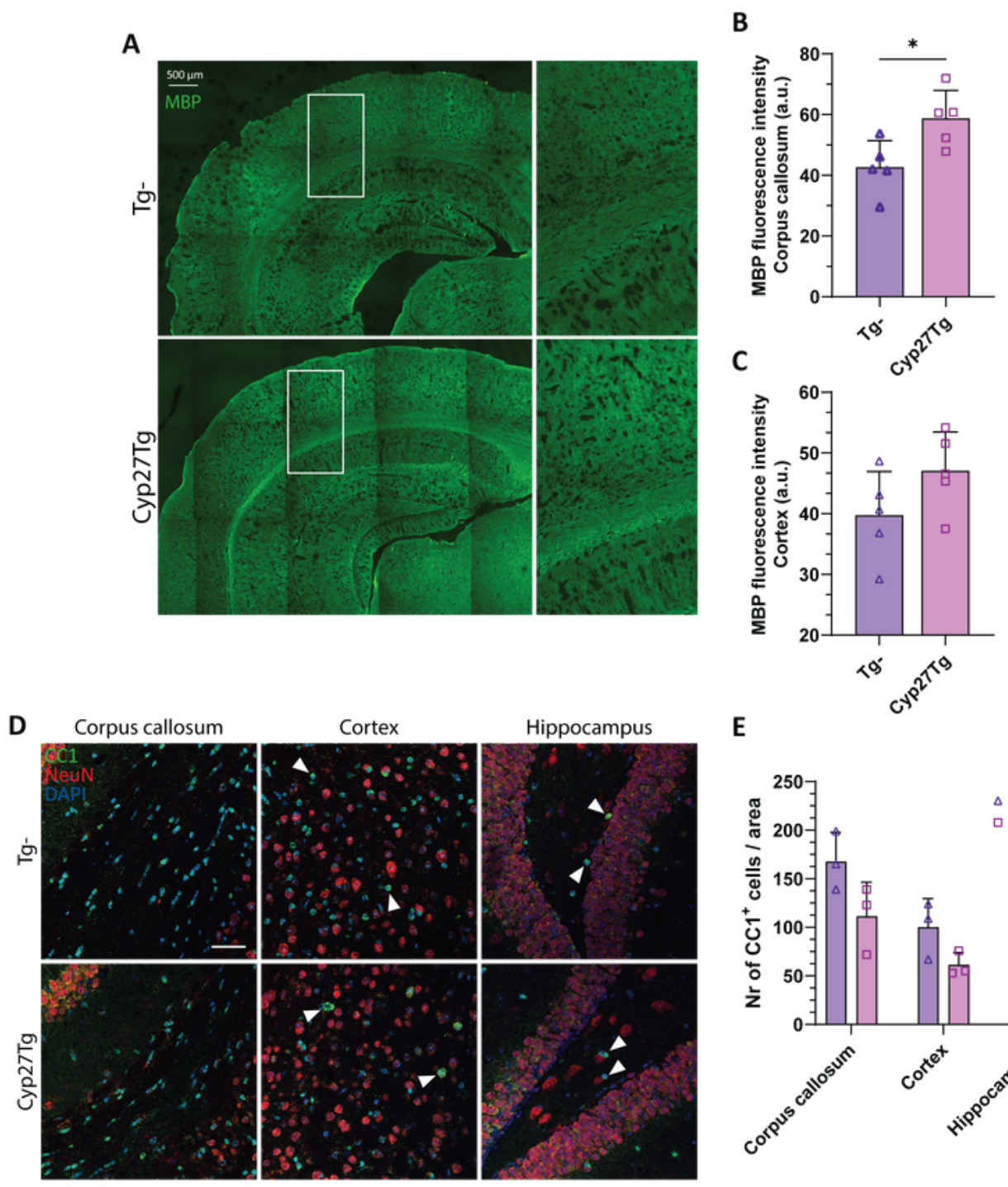

$\mathbf{E}$
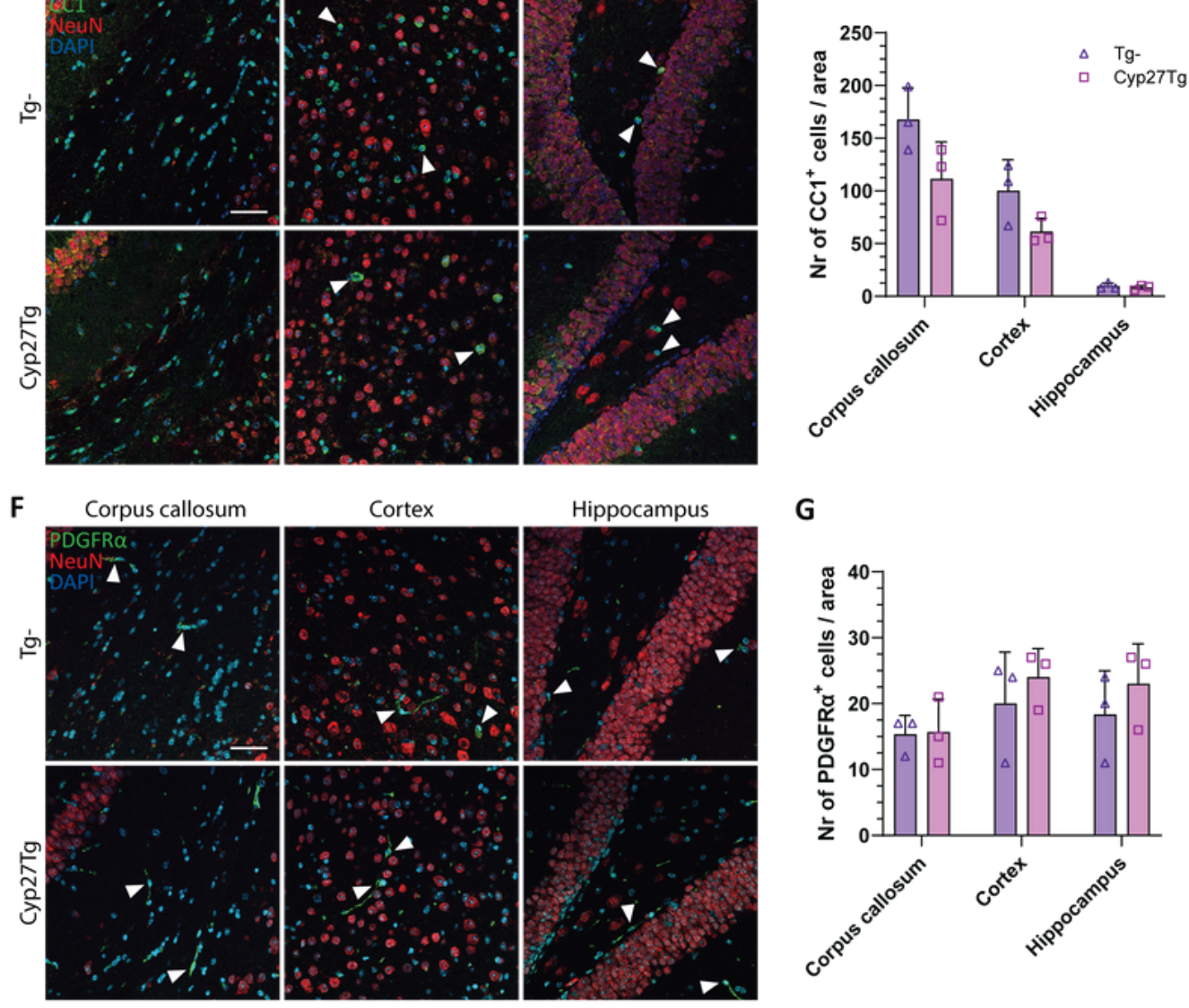

Figure 5 
Chronic exposure to 27-hydroxycholesterol (27-OH) increased myelin basic protein (MBP) levels in the corpus callosum but does not affect the numbers of immature or mature oligodendrocytes. (A) MBP staining in Tg- and Cyp27Tg brains. The intensity measures of MBP staining in (B) corpus callosum and (C) cortex. (D) Representative images of different brain regions from Cyp27Tg and Tg- mice. Brains were stained for $\mathrm{CC} 1$ (adenomatous polyposis coli clone 1), a marker for mature oligodendrocytes, and NeuN, a marker for neurons. White arrows indicate examples of $\mathrm{CC} 1$ positive cells. Scale bar $50 \mu \mathrm{m}$. (E) The numbers of $\mathrm{CC} 1+$ cells are similar between strains in all the different brain areas. $(\mathrm{F})$ Representative images of different brain regions from Cyp27Tg and $\mathrm{Tg}$ - mice. Brains were stained for PDGFRa (plateletderived growth factor receptor $\mathrm{a}$ ), a marker for immature oligodendrocytes, and NeuN. White arrows indicate examples of PDGFRa positive cells. Scale bar $50 \mu \mathrm{m}$. (G) The numbers of PDGFRa+ cells are similar between strains in all the different brain areas. In both $(E)$ and $(F)$ the total size of the area analysed was approximately $918 \mathrm{~mm} 2$. (B, D) unpaired Student's two-tailed t-test, all data presented as mean $\pm S D, * p<0.05$.
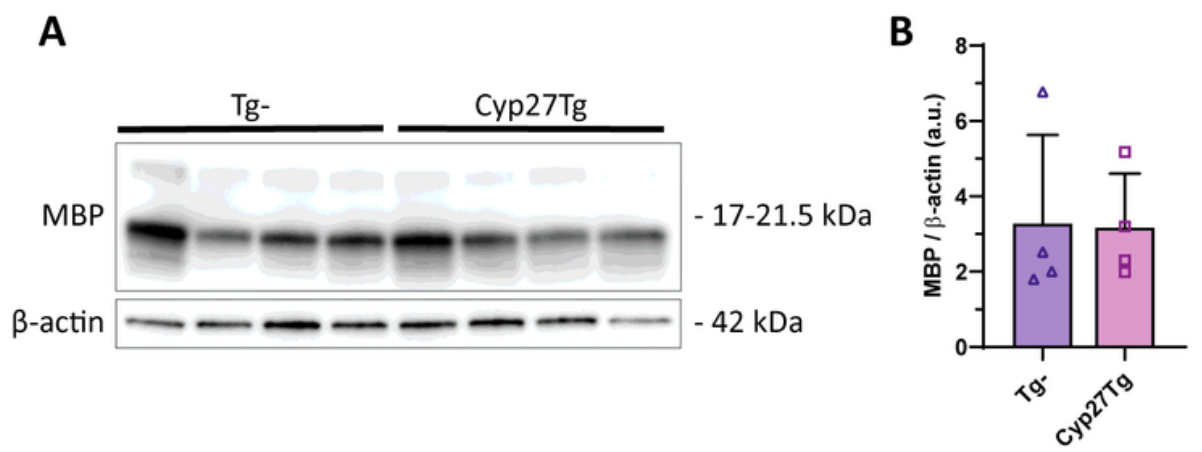

C

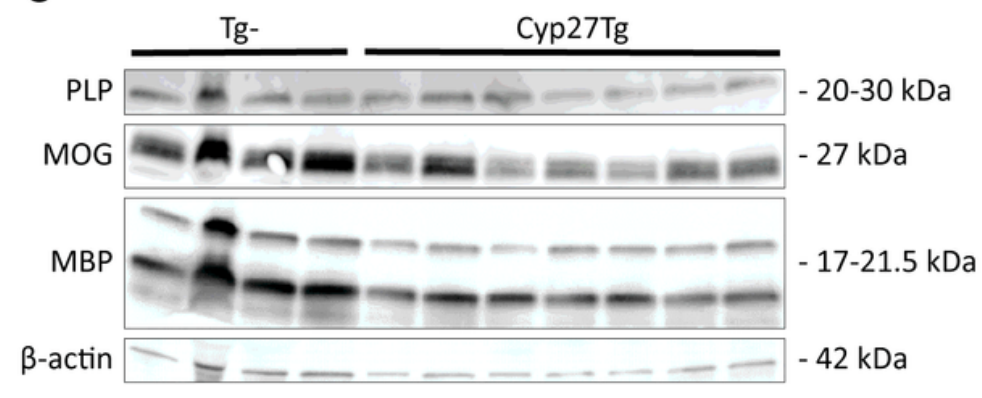

D

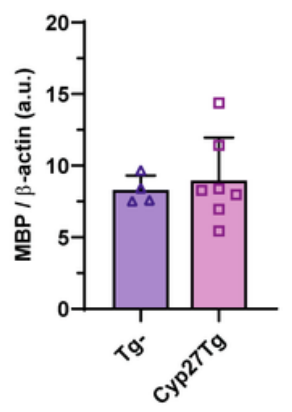

E

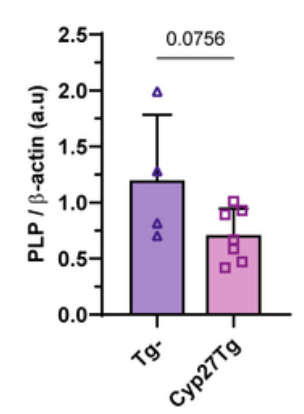

$\mathbf{F}$

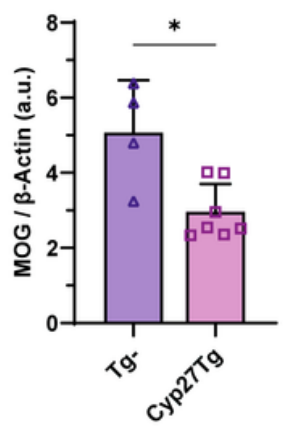

Figure 6

Western blot analysis of myelin proteins in the mouse brain. (A) Immunoblot of myelin basic protein (MBP) in total brain homogenates from Cyp27Tg and Tg- mice. (B) Quantification of MBP levels in total brain homogenates. (C) Immunoblots of the different myelin proteins in myelin enriched fractions from brain homogenates from the same mice. Quantification of (D) MBP, (E) proteolipid protein (PLP), and (F) myelin oligodendrocyte glycoprotein (MOG) levels in myelin enriched fractions. Myelin protein levels were normalised to $\beta$-actin. (B, F) Mann-Whitney U test two-tailed, (D, E) unpaired Student's two-tailed t-test, all data presented as mean $\pm S D$, $* p<0.05$. 


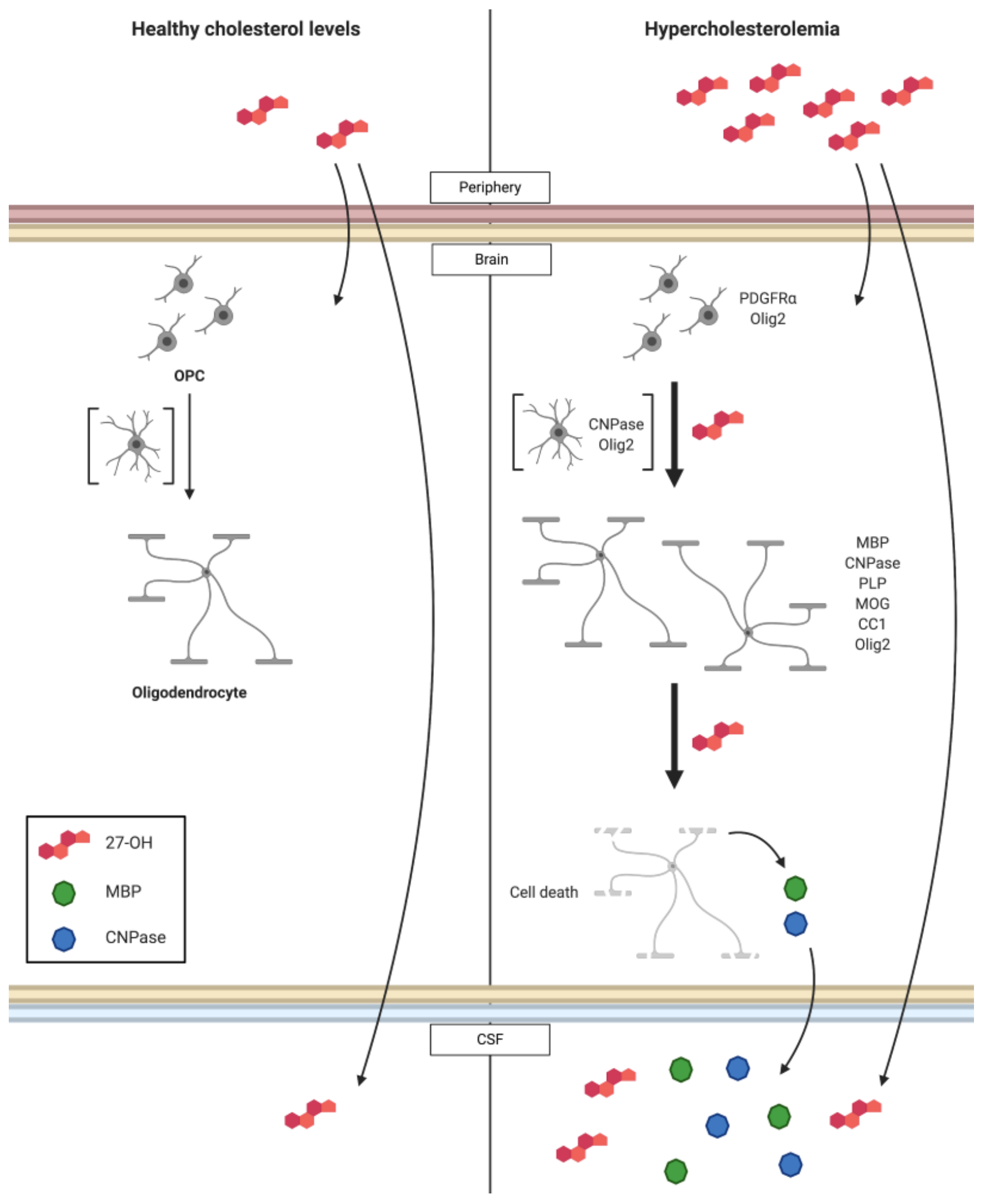

Figure 7

A postulated scenario of 27-hydroxycholesterol's (27-OH) impacts on oligodendrocytes in humans. Hypercholesterolemia results in increased peripheral concentrations of 27-0H. The oxysterol further traverses the blood-brain barrier into the brain and cerebrospinal fluid (CSF) in a concentration-dependent manner. Normally, oligodendrocyte progenitor cells (OPC) mature into myelinating oligodendrocytes during physiological myelin-turnover. However, it seems that 27-OH induces maturation reducing the OPC 
population, while it also contributes to the death of mature oligodendrocytes. Dying oligodendrocytes release proteins into the CSF. 